\title{
SOBRE LA PLENA VIGENCIA DE LA PRESUNCIÓN DE EQUIVALENCIA (BOSPHORUS) Y SU APLICACIÓN AL PRINCIPIO DE RECONOCIMIENTO MUTUO EN EL ESPACIO DE LIBERTAD, SEGURIDAD Y JUSTICIA
}

\author{
JOSÉ MANUEL CORTÉS MARTÍN' \\ jmcormar@upo.es
}

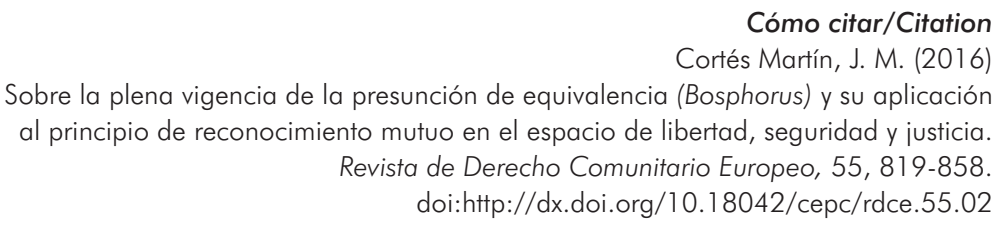

Resumen

El fallo del TEDH en el asunto Avotinšs contra Letonia reviste especial importancia porque es la primera vez desde el Dictamen del TJUE núm. 2/13 que el TEDH confirma la plena vigencia de la presunción de equivalencia. Asimismo, y quizás lo más importante, es la primera vez que aborda la convencionalidad del principio de confianza mutua, avalando la idea de que los órganos jurisdiccionales nacionales deben presumir la compatibilidad con los derechos fundamentales de las sentencias dictadas por los tribunales de otro Estado miembro. Es cierto, sin embargo, que advirtió de los riesgos de su aplicación mecánica porque pueden conducir a la constatación de una deficiencia manifiesta. Por ello, este fallo debe hacer reflexionar a las instituciones sobre la necesidad de emprender una reforma que homogeneice el grado de automaticidad del reconocimiento mutuo, insertando cláusulas implícitas de control en supuestos de deficiencias sistémicas. Desde una perspectiva más general, el TEDH

1 Profesor titular de Universidad, catedrático acreditado de Derecho Internacional Público de la Universidad Pablo de Olavide de Sevilla. 
desarrolla un alto grado de persuasión con esta forzada aplicación de la doctrina de la presunción de equivalencia a fin de tratar de despejar las múltiples dudas expresadas por el TJUE en el Dictamen núm. 2/13. Así, o bien se acepta por las demás partes en el CEDH de cara a una futura adhesión una cláusula como la propuesta del Comité MEIJERS o el TJUE acaba aceptando que fallos como Avotinš contra Letonia avalan una suficiente coordinación y toma en consideración de las peculiaridades del ELSJ porque al fin y al cabo el TEDH parece comprometerse a renunciar al escrutinio de los instrumentos del ELSJ basados en la confianza mutua en tanto en cuanto los jueces realicen un examen integrado de la protección de los Derechos fundamentales cada vez que se aleguen conculcaciones serias.

\title{
Palabras clave
}

CEDH; presunción de equivalencia; Espacio de Libertad, Seguridad y Justicia; principio de confianza mutua; principio de reconocimiento mutuo; Bosphorus; Avotinšs; adhesión de la UE al CEDH; insuficiencia manifiesta; Comité MEIJERS.

\section{THE BOSPHORUS PRESUMPTION REMAINS FULLY EFFECTIVE: ITS APPLICATION TO THE PRINCIPLE OF MUTUAL RECOGNITION IN THE AREA OF FREEDOM, SECURITY AND JUSTICE}

\begin{abstract}
The judgment in Avotinš vs. Latvia is particularly important. It is the first time since the ECJ Opinion n. 2/13 that the ECtHR confirms that the presumption of equivalence remains fully effective. Also, and perhaps most importantly, it is the first time it addresses the conventionality of the principle of mutual trust, supporting that national courts must presume the compatibility with human rights of judgments handed down by the courts of another Member State. It is true, however, that the ECtHR warns of the risks of its mechanical application because it could lead to consider that the protection of ECHR rights was manifestly deficient. Therefore, this judgment should give pause to the institutions on the need to undertake a reform, homogenizing the degree of automaticity of mutual recognition, by inserting implied control clauses in cases of systemic flaws. From a broader perspective, the ECtHR develops a high degree of persuasion with this forced application of the doctrine of equivalent protection in order to try clearing the many doubts expressed by the ECJ in Opinion 2/13. So, either it is accepted by the other parties to the ECHR in the framework of a future accession negotiation the MEIJERS Committee proposal or the ECJ accepts that judgments as Avotinš / Latvia guarantee a enough coordination and takes into account the peculiarities of the AFSJ. After all, the ECtHR seems committed to give up the scrutiny of the instruments of AFSJ based on mutual trust as long as the judges perform an integrated protection of fundamental rights review whenever serious violations are alleged.
\end{abstract}




\section{Keywords}

ECHR; equivalent presumption; Area of Freedom, Justice and Security; principle of mutual trust; principle of mutual recognition; Bosphorus; Avotin $\check{s}$; accession of the EU to the ECHR; protection of Convention rights manifestly deficient; MEIJERS Committee.

\section{LA PRESOMPTION D'EQUIVALENCE (BOSPHORUS) RESTE PLEINEMENT APPLICABLE: SON APPLICATION AU PRINCIPE DE RECONNAISSANCE MUTUELLE DANS L’ESPACE DE LIBERTÉ, DE SÉCURITÉ ET DE JUSTICE}

\section{Résumé}

L'arrêt Avotinš vs. Lettonie de la Cour Eur. DH est particulièrement importante. D'abord, depuis l'avis CJCE n. 2/13 la Cour confirme par la première fois que la présomption d'équivalence reste pleinement applicable. En suite, et peut-être plus important encore, il est la première fois qu'elle aborde la conventionalité du principe de la confiance mutuelle, en admettant l'idée que les juridictions nationales peuvent présumer la compatibilité avec les droits fondamentaux des jugements rendus par les tribunaux d'un autre État membre. Il est vrai, cependant, que la Cour de Strasbourg mis en garde contre les risques d'une application mécanique de ce principe, car elle peut conduire à la constatation d'une insuffisance manifeste. Par conséquent, cet arrêt devrait faire réfléchir aux institutions de l'Union européenne sur la nécessité d'entreprendre une réforme dirigée à homogénéiser le degré d'automaticité de la reconnaissance mutuelle, en insérant des clauses de contrôle implicites dans les cas de faiblesses systémiques. D'un point de vue plus large, la Cour développe un haut degré de persuasion avec cette application forcée de la doctrine de présomption d'équivalence afin d'essayer de dégager les nombreux doutes exprimés par la CJCE dans l'avis n. 2/13. Donc, dans le cadre d'une future adhésion, soit il est accepté par les autres parties à la CEDH une clause tel que proposée par le Comité MEIJERS, soit la CJUE accepte que des développements comme Avotiņš/Lettonie constituent une garantie de coordination suffisante, en prenant en considération les particularités de l'ELSJ. Après tout, la Cour EDH semble s'engager à renoncer à l'examen de conventionalité des instruments de l'ELSJ basées sur la confiance mutuelle, tant que les juges exercent une protection intégrée des droits fondamentaux chaque fois que des violations graves sont alléguées.

\section{Mots clés}

CEDH; présomption d'équivalence; Espace de liberté, de sécurité et de justice; principe de la confiance mutuelle; principe de reconnaissance mutuelle; Bosphorus; Avotiňš; adhésion de l'UE à la CEDH; insuffisance manifeste; Comité MEIJERS. 


\section{SUMARIO}

I. INTRODUCCIÓN. II. EL TEDH CONFIRMA LA PLENA VIGENCIA DE LA PRESUNCIÓN DE EQUIVALENCIA: LA STEDH AVOTINŠ/LETONIA: 1. Sobre el principio de la protección equivalente (Bosphorus). 2. Su aplicación al asunto Avotinš vs. Letonia.

3. La equivalencia del principio de reconocimiento mutuo en el espacio de libertad, seguridad y justicia. III. AVOTINSŠ, EL STATU QUO Y EL LARGO CAMINO HACIA LA ADHESION DE LA UNIÓN AL CEDH. IV. EL PRINCIPIO DE RECONOCIMIENTO MUTUO Y LAS JURISDICCIONES SUPREMAS NACIONALES: ¿̇UNA INCIPIENTE INSURRECCIÓN? V. CONCLUSIONES.

\section{INTRODUCCIÓN}

Plena vigencia para la presunción de equivalencia con el CEDH del sistema unionista de protección de los derechos fundamentales. Así se deduce del reciente fallo dictado por la Gran Sala del TEDH en el asunto Avotiňš vs. Letonia ${ }^{2}$ cuyos importantes desarrollos abordaremos en este trabajo. Para

2 TEDH, Avotinšr vs. Letonia, Sentencia [GS] de 23 de mayo de 2016, núm. 17502/07, ECHR:2016:0523JUD001750207. Sobre este fallo pueden verse los comentarios de: Sitian ØBY JOHANSEN, EU law and the ECHR: the Bosphorus presumption is still alive and kicking - the case of Avotins v v. Latvia, en http://eulawanalysis.blogspot.com. es/2016/05/eu-law-and-echr-bosphorus-presumption.html; Maxime BARBA, "Casse-tête jurisprudentiel autour de l'exequatur (A propos des arrêts Meroni et Avotiņšs)» y Jean Sylvestre BERGE, «Avotiņš ou le calme qui couve la tempête»; «Une, deux et... trois lectures: de l'avis 2/2013 (CJUE) à l'affaire Avotiņ̌̌ (CEDH)», en http://www. gdr-elsj.eu (consultados por última vez el 26 de octubre de 2016). De este último autor puede verse, asimismo: «Les rapports UE et Conv. EDH en matière de coopération judiciaire civile: entre rétrospective et prospective», RTD eur., núm. 2, 2014, pp. 361-371. Véase igualmente Laure MILANO, «Protection équivalente, une occasion manquée: CEDH, gr. ch., 23 mai 2016, núm. 17502/07, Avotiņ̌̌ c. Lettonie», La Semaine juridique: édition générale (JCP), vol. 90, núm. 24, 2016, pp. 1187 y ss.; Marta 
situar al lector, recordemos que cuando un Estado miembro de una organización internacional carece de discrecionalidad en la ejecución de sus obligaciones comunitarias, el TEDH ha venido estableciendo una presunción iuris tantum de compatibilidad del derecho de esa organización con los derechos protegidos en el CEDH si aquella otorga garantías equivalentes. Fue en el asunto Bosphorus vs. Irlanda la primera vez que el TEDH aplicó esta doctrina ${ }^{3}$, aunque ya gozaba de algún precedente ante la antigua Comisión Europea de Derechos Humanos ${ }^{4}$ y podría pensarse que se encontraba implícita de una $\mathrm{u}$ otra forma en el principio de subsidiariedad del sistema paneuropeo de garantías 5

REQUEJO ISIDRO, «On exequatur and the ECHR: Brussels I Regulation before the ECtHR", Praxis des Internationalen Privat— und Verfahrensrechts (IPRax), 2013, pp. 69-74; «Avotiňš c. Letonia, Sentencia del TEHD, de 23 de mayo de 2016, as. 17502/07», $R G D E$ (Iustel), núm. 40, 2016, pp. 187-202. Sobre la Sentencia de Sala, recaída el de 25 de febrero de 2014, puede verse el trabajo de Fernando GASCÓN INCHAUSTI, F., «El derecho procesal civil europeo comparece ante el Tribunal Europeo de Derechos Humanos: Reflexiones a partir de las resoluciones recaídas en los asuntos Povse c. Austria y Avotiňšc. Letonia», Cuadernos de Derecho Transnacional, vol. 6, núm. 2, 2014, pp. 91-111.

3 TEDH, Bosphorus Hava Yollari Turizm ve Ticaret AS vs. Irlanda [GS], núm. 45036/98, Sentencia de 30 de junio de 2005, ECHR:2005:0630JUD004503698, \$\$ 155-156. Sobre este fallo puede verse nuestro trabajo «Sobre el sistema unionista de protección de los Derechos humanos y la ruptura de su presunción de equivalencia con el CEDH», Revista de Derecho Comunitario Europeo, núm. 46, 2013, pp. 935-971; y la bibliografía allí citada.

4 Entre otros asuntos, Com. Eur. DH, M. \& Co. vs. Alemania, núm. 13258/87, Decisión de 9 de febrero de 1990, $D \& R$ 67, p. 138, ECHR:1990:0209DEC001325887. En esa época, la presunción estaba mucho menos elaborada, limitándose la Com. Eur. DH a constatar los progresos de las Comunidades Europeas en materia de Derechos fundamentales. Sin embargo, añadió de forma interesante en relación con la problemática del asunto que analizamos en este trabajo que había tenido en cuenta el hecho de que sería contrario a la misma idea de transferencia de competencias a una Organización obligar a sus miembros en cada caso particular a examinar si había sido respetado el art. $6 \mathrm{CEDH}$ antes de otorgar el exequátur a un fallo del TJCE. Con posterioridad, el TEDH daría un carácter más general al criterio de la equivalencia a partir del asunto Bosphorus vs. Irlanda.

5 En este sentido, el antiguo Presidente del TEDH, Jean Paul COSTA, «On the Legitimacy of the European Court of Human Rights' Judgments'", European Constitutional Law Review, vol. 7, núm. 2, 2011, pp. 173-182 (180). Sobre este importante principio, puede verse, entre otros: José Antonio PASTOR RIDRUEJO, «Le principe de subsidiarité dans la Convention europeìnne des droits de l'homme», en Jürgen 
En el marco de la adhesión de la UE al CEDH siguiendo el categórico mandato establecido en el art. 6 (2) TUE, algunos autores especularon sobre la continuidad de esta doctrina una vez vigente la adhesión, dado que conduce —en opinión de esos autores - a un doble estándar ${ }^{6}$ teniendo en cuenta que los Estados parte ajenos a la UE no se benefician de semejante presunción, dispongan o no de un sistema de protección con garantías equivalentes al $\mathrm{CEDH}^{7}$, o que esta presunción iría más allá de lo estrictamente necesario para respetar las características específicas del derecho de la Unión ${ }^{8}$. En realidad, estas dudas ya fueron expresadas por algunos magistrados en sus votos particulares adjuntos al fallo del TEDH en el asunto Bosphorus? ${ }^{9}$. Sin embargo,

BRÖHMER (coord.), Internationale Gemeinschaft und Menschenrechte: Festschrift fur Georg Ress zum 70, Heymann, Koln, 2005, pp. 1077-1083.

6 Véase, por ejemplo, Jean-François FLAUSS, «Le double standard dans la jurisprudence de la Cour européenne des droits de l'homme: ¿Fiction ou réalité?», en Andreas, AUER; Alexandre FLUECKIGER; Michel HOTTELIER, (eds.): Les droits de l'homme et la Constitution: Études en l'honneur du Professeur Giorgio Malinverni, Schulthess, Genéve, 2007, pp. 135-153. Algún autor ha deplorado que esta deferencia no se ofrezca también a los sistemas de protección nacionales, véase Nial FENNELLY, "Human Rights and the National Judge: His Constitution; The European Union; The European Convention», ERA Forum, 2011, pp. 87 y ss., p. 102.

7 Véase, entre otros, Leonard F. M. BESSELINK, «The European Union and the European Convention of Human Rights after the Lisbon Treaty: From Bosphorus Sovereign Immunity to full Scrutiny under the Reform Treaty?», en Ineke BOEREFIJN y Jenny E. GOLDSCHMIDT (eds.), Changing Perceptions of Sovereignity and Human Rights: Essays in Honour of Cees Funtermann, 2008, pp. 295-309; Fabienne KAUFF-GAZIN, "L'arrêt Bosphorus de la CEDH: quand le juge de Strasbourg décerne au système communautaire un label de protection satisfaisante des droits fondamentaux», Les Petites Affiches, 2005, núm. 234, p. 17; Geoff SUMNER, «We'll Sometimes Have Strasbourg: Privileged Status of Community Law Before the European Court of Human Rights», Irish Studies Law Review, vol. 16, 2008, pp. 127 y ss.

8 Véase, en este sentido, Thomas LOCK, «Walking on a Tightrope: The Draft ECHR Accession Agreement and the Autonomy of the EU Legal Order», CMLRev., 2011, pp. 1025 y ss. También la Comisión International de Juristas en el asunto TEDH, Senator Lines vs.Estados miembros de la UE, núm. 56672/00, (Déc.) [GS] de 10 de marzo de 2004, ECHR:2004:0310DEC005667200, exigió que se rechazara por falta de claridad esta doctrina, que en esa época era aplicada por la Comisión Eur. DH, TEDH, Senator Lines GmbH.

9 El CEDH exige, en efecto, que todas las partes sean tratadas en pie de igualdad, algo que el Juez Rozakis recordó en su voto particular en el asunto Bosphorus citando el asunto TEDH, Loizidou vs. Turquía [GS], (excepciones preliminares), (Déc.) de 23 
continuamos pensando que es improbable que el TEDH se desdiga de lo afirmado en el aquel asunto acerca de las necesidades de la integración y la cooperación en Europa, las cuales pueden justificar en determinadas parcelas un estándar de protección solo equivalente ${ }^{10}$. Es cierto, sin embargo, que teniendo en cuenta que la aplicación de esta doctrina no ha estado exenta de contradicciones e incoherencias ${ }^{11}$, quizás no sea descartable una cierta limitación de su alcance si la adhesión ve la luz algún día ${ }^{12}$.

Por otra parte, el Dictamen del TJUE núm. $2 / 13^{13}$, que ha dado al traste con casi todas las expectativas de adhesión de la Unión al CEDH al considerar el proyecto ${ }^{14}$ contrario a los tratados de la Unión por toda una serie de motivos, algunos de ellos difíciles de reconciliar, podría haber supuesto un punto

de marzo de 1995, núm. 15318/89, ECHR:1996:1218JUD001531889, \$77. En el asunto Avotinšs vs. Letonia pueden verse también las críticas a la doctrina Bosphorus en el voto disidente del Juez András SAJÓ adjunto al fallo.

10 En este sentido, Johan CALLEWAERT, «Les voies de recours communautaires sous l'angle de la Convention européenne des droits de l'homme: la portée procédurale de l'arrêt Bosphorus", en Lucius CAFLISCH [et al.], Human Rights, Democracy and the Rule of Law: Liber Amicorum Luzius Wildhaber, Dike, Nomos, Zurich, Baden-Baden, 2007, pp. 115-131, p. 130.

11 Cf. José Manuel CORTÉS MARTÍN, «Sobre el sistema unionista ...», op. cit.,nota 3; Thomas LOCK, «The ECJ and the ECtHR: The Future Relationship between the Two European Courts", The Law and Practice of International Courts and Tribunals, vol. 8, 2009, pp. 375-398.

12 Basándose fundamentalmente en la ausencia de escrutinio del derecho originario por parte del TJUE, algunos piensan que esta doctrina continuará tras la adhesión, aunque no como criterio de admisibilidad, sino como estándar rationae materiae, véase Paul DE HERT y Fisnik KORENICA, «The Doctrine of Equivalent Protection: Its Life and Legitimacy Before and After the European Union's Accession to the European Convention on Human Rights», German Law Journal, vol. 13, núm. 7, 2012, pp. 874-895. A favor de su redefinición y su generalización, Olivier DE SCHUTTER, The Two Lives of Bosphorus: Redefining the Relationships between the European Court of Human Rights and the Parties to the Convention, CRIDHO Working Paper 2013/6, http://cridho.uclouvain.be (consultado por última vez el 26 de octubre de 2016).

13 Dictamen TJUE núm. 2/13, de 18 de diciembre de 2014, EU:C:2014:2454. Sobre este Dictamen puede verse nuestro trabajo, «Autonomía versus sumisión a un control externo en materia de Derechos fundamentales: consideraciones sobre el Dictamen TJUE núm. 2/13 relativo a la adhesión al CEDH», RGDE (Iustel), núm. 37, 2015, pp. 1-49; y la bibliografía allí citada.

14 El consenso sobre el proyecto de adhesión entre los cuarenta y siete Estados parte del Consejo de Europa y la Unión había sido alcanzado el 5 de abril de 2013. 
de inflexión en las relaciones de cooperación y deferencia mutua mantenidas hasta ahora por ambas jurisdicciones, hasta el punto de que algunos se aventuraron a conjeturar una contundente respuesta del TEDH materializada en el fin de la presunción con respecto a la Unión ${ }^{15} \mathrm{o}$, al menos, su flexibilización para que la imposibilidad de llevar a cabo la adhesión no permitiera supuestos de indefensión ante asuntos puramente comunitarios, es decir, aquellos que desafían la legalidad de las medidas nacionales de implementación de actos de la Unión que no dejan ninguna discrecionalidad a los Estados miembros, mediante una interpretación más amplia de la noción de protección manifiestamente deficiente ${ }^{16}$. La mayoría dedujo esta suposición de las palabras vertidas por el presidente del TEDH en el discurso de apertura del año judicial 2015 del TEDH cuando al comentar la decepción que le había provocado este Dictamen, afirmó que para evitar a toda costa lagunas en esta protección en el espacio jurídico del CEDH, el Tribunal de Estrasburgo hará todo lo posible para garantizar la protección de los derechos fundamentales de los ciudadanos europeos, con independencia de que la violación sea atribuible a un Estado parte o a una organización internacional, añadiendo que el TEDH continuará

15 Por ejemplo, Javier GONZALEZ VEGA, «La 'teoría del big bang’ o la creciente distancia entre Luxemburgo y Estrasburgo», La Ley Unión Europea, núm. 25, 2015, pp. 17-50, p. 34; se pregunta si a la luz del Dictamen TJUE núm. 2/13 podría cuestionarse la balsámica posición en torno al control de la acción de la UE; sentido en el que también se pronuncian, aunque de forma más general a propósito del asunto Bosphorus, Araceli MANGAS MARTÍN y Diego Javier LIÑÁN NOGUERAS, Instituciones y Derecho de la Unión Europea, 7. ${ }^{a}$ ed., Tecnos, Madrid, 2012, p. 134. El Dictamen TJUE núm. 2/13 también llevó a otros autores a cuestionar su continuidad, Véase Maribel GONZÁLEZ PASCUAL, "Secreto profesional de los abogados y blanqueo de capitales: la normativa de la Unión ante el TEDH», Revista Española de Derecho Constitucional, núm. 101, 2014, pp. 381-404; Jean Paul JACQUÉ, Que faire après l'avis 2/13 de la Cour de Justice:?, http://www.droit-union-europeenne.be/421312988 (consultado por última vez el 26 de octubre de 2016); Cedric RYNGAERT, «Oscillating between embracing and avoiding Bosphorus...", op. cit.,nota 3, pp. 176-192; Olivier DE SHUTTER, «Bosphorus post-accession: Redefining the Relationships between the European Court of Human Rights and the Parties to the Convention", en Vasiliki KOSTA; Nikos SKOUTARIS y Vassilis P. ZEVELEKOS, The EU Accession to the ECHR, Hart Publishing, Oxford, 2014, pp. 177-198, p.198, refiriéndose a un escenario postadhesión, señala que no sería ni jurídica, ni políticamente justificado mantener la doctrina Bosphorus en su forma tradicional porque situaría a la Unión en una situación privilegiada.

16 Cf. Eleanor SPAVENTA, «A Very Fearful Court? The Protection of Fundamental Rights in the European Union after Opinion 2/13", Maastricht Journal of European and Comparative Law (MJ), vol. 22, núm. 1, 2015, pp. 35-56, p. 55. 
valorando si los actos estatales, con independencia de su origen, cumplen o no con el $\mathrm{CEDH}^{17}$.

Sin embargo, el TEDH ha confirmado plenamente la vigencia de esta doctrina en el asunto Avotinšs vs. Letonia, importante desarrollo al que dedicaremos la primera parte de este trabajo. Pero si importante es esta confirmación frente a las especulaciones ya citadas, más lo es — pensamos- su aplicación al principio de confianza mutua entre los Estados miembros, el cual reviste una importancia primordial una vez que el TJUE lo elevara a rango constitucional en el Dictamen núm. $2 / 13^{18}$; y su corolario el principio de reconocimiento mutuo en el marco del Espacio de Libertad, Seguridad y Justicia (ELSJ). Y ello porque es la primera vez que el TEDH aborda de forma sustancial el respeto de las garantías del procedimiento en el contexto de este principio ${ }^{19}$. Como es sabido, se trata de una cuestión controvertida porque la protección de los derechos fundamentales en los distintos Estados miembros es equivalente, no idéntica, lo que inevitablemente crea una tensión entre confianza mutua y protección de estos derechos que en los últimos tiempos viene manifestándose de forma recurrente ante el TEDH ${ }^{20}$ y provocando una aparente insurrección por parte de algunas jurisdicciones supremas. Finalmente, en este trabajo intentaremos demostrar que por paradójico que parezca, en un asunto como Avotinšs vs. Letonia la adhesión de la Unión al CEDH habría reportado más ventajas para salvaguardar la autonomía del derecho de la Unión —como el

17 A lo que añadió: «The essential thing, in the end, is not to have a hierarchical conception of systems that would be in conflict with each other. No, the key is to ensure that the guarantee of fundamental rights is coherent throughout Europe», en www. echr.coe.int/Documents/Speech_20150130_Solemn_Hearing_2015_ENG.pdf, p. 5 (consultado por última vez el 26 de octubre de 2016).

18 Dictamen TJUE núm. 2/13, apartados 191-194.

19 En el fallo del TEDH en el asunto Povse vs. Austria, 30696/09, (déc.) de 18 de junio de 2013, ECHR:2013:0618DEC000389011, hubo más bien una aplicación mecánica de la presunción, a pesar de que la problemática planteada afectaba al Reglamento Bruselas II bis, también basado en el principio de reconocimiento mutuo (Reglamento CE núm. 2201/2003, de 27 de noviembre de 2003, relativo a la competencia, el reconocimiento y la ejecución de resoluciones en materia matrimonial y de responsabilidad parental, DOL 338/1).

20 Entre otros asuntos, TEDH, M. S. S. vs. Bélgica y Grecia [GS], núm. 30696/09, Sentencia de 21 de enero de 2011, ECHR:2011:0121JUD003069609. Puede verse, entre otros: Silvia MORGADES GIL, S., «TEDH — Sentencia de 21.01.2011 (Gran Sala), M. S. S. c. Bélgica y Grecia, 30696/09 - El funcionamiento efectivo de la política europea de asilo ante la garantía del derecho a no sufrir tratos inhumanos o degradantes del CEDH», Revista de Derecho Comunitario Europeo, núm. 41, 2012, pp. 183-204. 
TJUE preservó a toda costa en su Dictamen núm. 2/13 - que el statu quo, es decir, el examen de convencionalidad del derecho de la Unión por la intermediación de los Estados parte miembros de la Unión.

\section{EL TEDH CONFIRMA LA PLENA VIGENCIA DE LA PRESUNCIÓN DE EQUIVALENCIA: LA STEDH AVOTINŠ VS. LETONIA}

\section{SOBRE EL PRINCIPIO DE LA PROTECCIÓN EQUIVALENTE (BOSPHORUS)}

En la actualidad existe una multitud de organizaciones internacionales que crean sus propias reglas internas, se benefician de inmunidades y engendran nuevas obligaciones para sus miembros. Como consecuencia de ello, es muy probable que sus miembros se vean confrontados a divergencias en sus obligaciones dimanantes, de una parte, del CEDH; y de otra, del marco jurídico diamante de esa organización. Era necesario, por tanto, que el TEDH definiera un enfoque de principio para tratar este tipo de asuntos, creando una doctrina que resolviera aquellos asuntos en los que un conflicto de obligaciones priva a los Estados parte de la discrecionalidad necesaria para conformarse a las exigencias dimanantes del CEDH. Y esta es la función que cumple la doctrina Bosphorus, cuyo propósito es evitar que un Estado parte se vea confrontado a un dilema frente a obligaciones jurídicas procedentes de diversas fuentes. Asimismo, tiende a determinar los casos en los que el Tribunal de Estrasburgo en nombre de la cooperación internacional puede reducir la intensidad de su control, atenuación que solo puede llevarse a cabo en la medida en que los derechos y garantías del CEDH se beneficien de un control «comparable» al desarrollado por el TEDH ${ }^{21}$.

Así pues, las partes contratantes permanecen siendo responsables del cumplimiento del CEDH en relación con las medidas derivadas de la necesidad de respetar sus obligaciones jurídicas internacionales, incluso si estas obligaciones se enmarcan en la pertenencia a una organización internacional a la que han transferido parte de sus competencias soberanas ${ }^{22}$, aunque para conciliar esta posición con la realidad de la cooperación internacional, la medida de un Estado parte adoptada en ejecución de semejantes obligaciones jurídicas internacionales debe reputarse justificada si la organización en cuestión otorga una protección al menos equivalente o comparable a la otorgada

21 Entre otros asuntos, Com. Eur. DH, M. \& Co.

22 TEDH, Bosphorus vs. Irlanda, $\$ 153$. 
por el CEDH, incluyendo tanto garantías sustanciales como mecanismos de control $^{23}$.

Sin embargo, esta equivalencia o marchamo de legitimidad en materia de protección otorgado por el TEDH no es ni mucho menos absoluta, sino que siempre ha constituido una presunción iuris tantum que puede revertirse si en un determinado asunto se demuestra una deficiencia manifiesta de esta protección ${ }^{24}$, como así ha ocurrido ya en varios fallos ${ }^{25}$. Así ocurre cuando el acto en cuestión no puede enmarcarse en las obligaciones jurídicas internacionales del Estado miembro, en particular, cuando ha desempeñado una potestad discreciona ${ }^{26}$. Y, en segundo lugar, cuando la protección de los derechos garantizados por el CEDH es manifiestamente deficiente, comprobación que llevará al TEDH a examinar las violaciones en materia de derechos humanos, aunque garantizando al mismo tiempo que quede preservada la cooperación internacional.

En relación con la Unión Europea, no creemos que la presunción se aplique a todo el derecho de la Unión, sino que dependerá de los ámbitos, del grado de discrecionalidad de la que gocen las autoridades nacionales y, especialmente, de la posibilidad de que el TJUE pueda intervenir para proteger los derechos fundamentales ${ }^{27}$. Pero a pesar de estas limitaciones, lo cierto es que

23 Ibid., \$\$ 152-155. Asimismo, TEDH, Behrami y Behrami vs. Francia y Saramati vs. Francia, Alemania y Noruega (Déc.) [GS], de 2 de mayo de 2007, núm. 71412/01 y 78166/01, ECHR:2007:0502DEC007141201, \$ 145; y Michaud/Francia, núm. 12323/11, \$\$ 102-104, CEDH 2012-VI, ECHR:2012:1206JUD001232311.

24 TEDH, Bosphorus vs. Irlanda, \$72, \$\$ 155-156.

25 TEDH Michaud vs. Francia; Dhahbi vs. Italia, núm. 17120/09, de 8 de abril de 2014, ECHR:2014:0408JUD001712009; Schipani y otros vs. Italia, núm. 38369/09, de 21 de julio de 2015, ECHR:2015:0721JUD003836909. Próximamente, el TEDH tendrá que examinar el asunto Repcevivág Szövetvezet vs. Hungría, núm. 70750/14, nuevamente sobre la conculcación del CEDH por no planteamiento de una cuestión prejudicial, esta vez por parte de una jurisdicción constitucional, http://hudoc.echr. coe.int/eng?i=001-157462 (consultado por última vez el 26 de octubre de 2016).

La presunción no se aplica con respecto a los actos de una organización internacional cuyo vínculo con el Estado miembro es simplemente la presencia en su territorio de una sede de la organización puesto que en semejantes casos esos actos no pueden enmarcarse en la jurisdicción del Estado de sede, supuesto de los Países Bajos con respecto a la Tribunal Penal Internacional para la Antigua Yugoslavia, Blagojevi vs. Países Bajos (déc.), núm. 49032/07, ECHR:2009:0609DEC004903207, \$ 46, de 9 de junio de 2009, Galić vs. Países Bajos (déc.), núm. 22617/07, de 9 de junio de 2009, ECHR:2009:0609DEC002261707, \$\$ 46 y 48.

27 TEDH, Bosphorus vs. Irlanda, $\$ 153$. 
esta doctrina ha permitido ir salvando la mayoría de las incoherencias e incertidumbres del sistema unionista de protección de los derechos fundamentales.

Ahora bien, nunca esta presunción fue concebida para aplicarse exclusivamente a la Unión ${ }^{28}$. Por el contrario, el TEDH ha realizado una aplicación amplia a fin de superar un problema fundamental como es el hecho de que las organizaciones internacionales no son signatarias de la mayoría de tratados en materia de derechos humanos. De ahí que la doctrina se haya desarrollado en favor de la cooperación internacional ${ }^{29}$. A veces, implícitamente o incluso de forma explícita, el TEDH no ha dejado de aplicar la doctrina Bosphorus a otras organizaciones internacionales distintas de la Unión como Naciones Unidas ${ }^{30} \mathrm{o}$ la OTAN ${ }^{31}$... Así, ha rechazado en virtud del art. $35 \$ 4 \mathrm{CEDH}$ las quejas sobre los actos de la Misión de la ONU para la administración interina de Kosovo ${ }^{32}$,

28 En relación con la Unión, el TEDH aplicó claramente la presunción antes de concluir que los actos no eran atribuibles al Estado parte defensor en los asuntos Bosphorus vs. Irlanda, Biret vs. Francia, Michaud vs. Francia, Cooperativa de agricultores de Mayenne y Cooperativa lechera Maineanjou vs. Francia, núm. 16931/04, (déc.) de 10 de octubre de 2006, Connolly vs. Estados miembros de la UE (déc.), núm. 73274/01, de 9 de diciembre de 2008, ECHR:2008:1209DEC007327401; Producentenorganisatie van de Nederlandse Kokkelvisserij U.A. vs. Paises Bajos (déc.), núm. 13645/05, de 20 de enero de 2009, ECHR:2009:0120DEC001364505; Povse vs. Austria; Andreasen vs. Estados miembros de la UE (déc.), núm. 28827/11, de 31 de marzo de 2015, ECHR:2015:0331DEC002882711.

29 Compárense los fallos del TEDH en los asuntos Bosphorus vs. Irlanda, \$\$ 152-155 y Michaud vs. Francia, \$\$ 102-104.

30 TEDH, Pérez vs. Alemania, $\$$ 66. Aunque nada parece impedir la aplicabilidad de esta metodología al Consejo de Seguridad de la ONU cuando adopta resoluciones que incorporan decisiones ordenando la congelación de fondos de aquellos sospechosos de financiar el terrorismo internacional, el TEDH ha sido hasta ahora reticente, prefiriendo adoptar otro tipo de presunciones como la adoptada en el asunto Al-Jedda vs. Reino Unido, $\$ 102$, relativa a la interpretación de las decisiones obligatorias de la ONU; o la presunción Nada vs. Suiza, relativa a la discrecionalidad del Estado miembro en la ejecución de las decisiones obligatorias de la ONU. Esta deriva está posiblemente influenciada por un argumento político, según el cual, la ONU sería una organización tan particular que debería disfrutar de un trato privilegiado frente a otras organizaciones internacionales, posición definida en el asunto Behrami y Saramati vs. Francia, Alemania y Noruega, frente a lo que podría deducirse de Bosphorus vs. Irlanda; o en el asunto Stichting Mothers of Srebrenica y otros vs. Países Bajos (déc.), núm. 65542/12, ECHR:2013:0611DEC006554212; frente a lo que podría deducirse de Waite y Kennedy vs. Alemania [GS], núm. 26083/94, de 16 de marzo de 1998, ECHR:1999:0218JUD002608394.

31 TEDH, Gasparini vs. Italia y Bélgica.

32 TEDH, Behrami vs. Francia, Alemania y Noruega. 
la administración civil internacional en Bosnia-Herzegovina ${ }^{33}$, el Tribunal Administrativo de la OIT, el Tribunal Administrativo de la Organización Europea para la Seguridad de la Navegación Aérea ${ }^{34}$, el Tribunal Penal Internacional para la Antigua Yugoslavia ${ }^{35}$, la Corte Penal Internacional ${ }^{36}$, el Consejo Oleícola Internacional ${ }^{137}$ o la Oficina Europea de Patentes ${ }^{38}$. Y el mismo razonamiento ha sido aplicado incluso al Tribunal Administrativo del Consejo de Europa ${ }^{39}$.

Conviene añadir que según el tipo de procedimiento en una organización internacional la presunción va a recibir una aplicación modulada. Cuando el demandante alega fallos estructurales en el seno de los mecanismos internos de la organización internacional en cuestión, el TEDH aplica la lógica Bosphorus retrospectivamente como si verificara si los Estados, el día de la transferencia de una parte de sus competencias soberanas a la organización internacional, se hubieran asegurado de que los derechos garantizados por el CEDH recibirían una protección equivalente ${ }^{40}$. Así, el principio de la protección equivalente se aplica de forma diferente en los asuntos relativos a la Unión, según se trate de conflictos laborales en el seno de la Comisión Europea ${ }^{41}$; de la ejecución

33 TEDH, Beri y otros vs. Bosnia-Herzégovina (déc.), núm. 36357/04, de 16 de octubre de 2007, ECHR:2007:1016DEC003635704, \$30, reproduciendo el razonamiento del asunto Behrami.

TEDH, Boivin vs. Estados miembros del Consejo de Europa.

35 TEDH, Galic vs. Países Bajos (déc.), nº 22617/07, de 9 de junio de 2009, ECHR:2009:0609DEC002261707. En $\$ 46$, el TEDH se hace eco claramente de la doctrina Bosphorus.

36 TEDH, Djokaba Lambi Longa vs. Paises Bajos (déc.), núm. 33917/12, CEDH 2012, ECHR:2012:1009DEC003391712. Nuevamente, en el \$79 el TEDH se inspira claramente en la doctrina Bosphorus.

37 TEDH, López Cifuentes vs. España (déc.), núm. 18754/06, de 7 de junio de 2009, ECHR:2009:0707DEC001875406.

38 TEDH, Klauseckervs. Alemania (déc.), no 415/07, de 6 de enero de 2015, ECHR:2015:0106DEC000041507; Com. Eur. DH, Lenzing AG vs. Alemania, núm. 39025/97, (déc.) de 9 de septiembre de 1998, ECHR:1998:0909DEC003902597, Lenzing AG vs. Reino Unido, (déc.) núm. 38817/97, de 9 de septiembre de 1998, ECHR:1998:0909DEC003881797; Rambus Inc. vs. Alemania (déc.), núm. 40382/04, de 16 de junio de 2009, ECHR:2009:0616DEC004038204.

39 TEDH, Beygo vs. Estados miembros del Consejo de Europa (déc.), núm. 36099/06, de 16 de junio de 2009, ECHR:2009:0616DEC003609906. El razonamiento es similar al seguido en el asunto Boivin vs. Estados miembros del Consejo de Europa.

40 Véase, por ejemplo, TEDH, Gasparin vs. Italia y Bélgica.

41 TEDH, Connolly vs. Estados miembros de la UE; Andreasen vs. Estados miembros de la $U E$. 
regular del derecho derivado ${ }^{42}$ o de la aplicación del derecho originario ${ }^{43}$. En cuanto a la Oficina Europea de Patentes, el TEDH distingue en cuanto a la equivalencia de la protección ofrecida por la organización en el procedimiento interno de solución de conflictos laborales ${ }^{44} \mathrm{y}$ en lo relativo al reconocimiento y retirada de una patente ${ }^{45}$. De manera similar, el TEDH desarrolla exámenes diferentes según se trate de resoluciones del Consejo de Seguridad ${ }^{46} \mathrm{o}$ del procedimiento de solución de litigios en materia laboral que implicaban al secretario general de esta organización ${ }^{47}$. Teniendo en cuenta la influencia prácticamente inexistente del Estado miembro en el marco de esos conflictos internos, el TEDH se limita a examinar si los Estados que se adherían a esa organización pensaron de buena fe que sería otorgada una protección equivalente al CEDH. Si este es el caso, el TEDH considera que la parte contratante ha cumplido las obligaciones que se deducen del $\mathrm{CEDH}$ al adherirse a esa organización, presunción que puede romperse si es posible demostrar que la protección ofrecida por esa organización es manifiestamente deficiente ${ }^{48}$.

En cuanto al ámbito material de la doctrina Bosphorus hay que decir que ningún capítulo de los ordenamientos jurídicos de los Estados parte puede sustraerse al escrutinio del TEDH. Por consiguiente, también los instrumen-

42 TEDH, Cooperatieve Producentenorganisatie van de Nederlandse Kokkelvisserij U.A. vs. Paises Bajos; Povse vs. Austria.

43 TEDH, Matthews vs. Reino Unido [GS], núm. 24833/94, CEDH 1999-I, ECHR:1999:0218JUD002483394.

44 TEDH, Klausecker vs. Alemania (déc.), núm. 415/07, de 6 de enero de 2015, ECHR:2015:0106DEC000041507.

45 Com. Eur. DH, Lenzing AG vs. Alemania, núm. 39025/97, (déc.) de 9 de septiembre de 1998, CHR:1998:0909DEC003902597, Lenzing AG vs. Reino Unido, (déc.) núm. 38817/97, de 9 de septiembre de 1998, ECHR:1998:0909DEC003881797; Rambus Inc. vs. Alemania (déc.), núm. 40382/04, de 16 de junio de 2009, ECHR:2009:0616DEC004038204.

46 TEDH, Behrami y Behrami vs. Francia y Saramati vs. Francia, Alemania y Noruega, $\$ 145$, Beri y otros vs. Bosnia-Herzégovina (déc.), núm. 36357/04, de 16 de octubre de 2007, ECHR:2007:1016DEC003635704, Al-Jedda vs. Reino Unido [GS], num. 27021/08, ECHR:2011:0707JUD002702108, \$102, CEDH 2011; Nada vs. Suiza [GS], núm. 10593/08, CEDH 2012-V, ECHR:2012:0912JUD001059308.

47 TEDH, Pérez vs. Alemania (déc.), núm. 15521/08, 6 de enero de 2015, ECHR:2015:$0106 \mathrm{DEC} 001552108$.

48 TEDH, Boivin vs. Estados miembros del Consejo de Europa (déc.), núm. 73250/01, ECHR:2008:0909DEC007325001; Connolly vs. Estados miembros de la UE; Gasparini vs. Italia y Bélgica (déc.), núm. 10750/03, de 12 de mayo de 2009, ECHR:2009:0512DEC001075003; Rambus Inc. vs. Alemania; Klausecker vs. Alemania, \$97, Pérez vs. Alemania, $\$ 62 ;$ Andreasen vs. Estados miembros de la UE, $\$ 73$. 
tos internacionales de cooperación quedan sometidos a su control. Es precisamente con este fin que la doctrina Bosphorus establece un doble criterio de carácter procesal y material. En el marco de la admisión del recurso, la presunción entraña la identificación de una acción, omisión o conducta relevante de la jurisdicción del Estado parte defensor, al cual le viene impuesta por otros tratados sin poder discrecional.

En el examen del fondo, la doctrina Bosphorus implica una comparación del mecanismo material de garantías de los derechos fundamentales y de los mecanismos de protección previstos por el CEDH y por el sistema jurídico de la organización internacional. Dicha comparación se funda sobre la presunción iuris tantum de compatibilidad con el CEDH siempre que no se establezca una insuficiencia manifiesta del orden jurídico de la organización internacional.

A modo de conclusión puede decirse que todos estos fallos no vienen sino a demostrar, de una parte, que la presunción ofrece una solución que permite reducir las disparidades entre les obligaciones internacionales de los Estados parte cuando los dos sistemas aplicables garantizan una protección análoga, incluso si esta protección no es idéntica, sino solo comparable; $y$, de otra, el alto grado de flexibilidad que el TEDH ha aplicado a esta doctrina, lo cual le permite encontrar soluciones audaces a los supuestos de confrontación de obligaciones para los Estados miembros.

\section{SU APLICACIÓN AL ASUNTO AVOTINY̌ VS. LETONIA}

En mayo de 1999, el ciudadano letón Pēteris Avotiņ̌̌ recibió de la empresa F.H. Ltd. un préstamo de 100.000 dólares, comprometiéndose a devolverlo junto con los intereses antes del 30 de junio de 1999. El contrato se regía por el derecho chipriota, aunque los tribunales de este país no gozaban de jurisdicción exclusiva para resolver las controversias que pudieran surgir. Ante el impago del préstamo, la empresa acreedora planteó en 2003 un litigio contra el deudor ante los tribunales chipriotas. Dado que el Sr. Avotiņš no residía en Chipre, se le envió una citación para comparecer a través de las autoridades letonas, la cual no fue aparentemente recibida por el demandado. Pese a su aparente ausencia del litigio, los tribunales chipriotas dictaron Sentencia en mayo de 2004 en la que le condenaban al pago y en la que se señalaba expresamente que el demandado no había comparecido pese a haber sido correctamente citado. En febrero de 2015, la empresa acreedora planteó ante los tribunales letones el reconocimiento y ejecución de esta Sentencia. En un primer momento, este reconocimiento fue rechazado dadas las discrepancias sobre la dirección correcta del Sr. Avotin, šs aunque en apelación la ejecución fue aceptada inaudita parte. Según el Sr. Avotin, š, no tuvo conocimiento de 
la Sentencia del juzgado chipriota hasta el 15 de junio de 2016, momento en que impugnó el reconocimiento alegando la violación tanto el art. 34.2 del Reglamento Bruselas I ${ }^{49}$ como el derecho civil letón. El Tribunal Regional de Letonia casó su recurso, paralizando el reconocimiento por faltar el certificado exigido en el art. 54 del Reglamento Bruselas I. Subsanado este requisito en apelación por la empresa acreedora, el Tribunal Supremo letón aceptó finalmente su ejecución, afirmando que en el marco del Reglamento Bruselas I bajo ninguna circunstancia la Sentencia de origen puede ser revisada en cuanto a su sustancia ${ }^{50}$. Fue entonces cuando el Sr. Avotin, š planteó un recurso ante el TEDH contra Letonia y Chipre, siendo este último rechazado por extemporáneo. En su demanda alegó que el Tribunal Supremo de Letonia había infringido el derecho a un proceso equitativo al reconocer y ejecutar la Sentencia chipriota porque en su opinión conculcaba sus derechos de defensa ${ }^{51}$. La Comisión Europea participó en el proceso ante la Gran Sala como tercero interviniente alegando la plena aplicabilidad de la doctrina de la presunción equivalente y la compatibilidad del Reglamento Bruselas I con el art. 6 CEDH.

En su Sentencia, la Gran Sala del TEDH señala, en primer lugar, que el art. $6 \mathrm{CEDH}$ es plenamente aplicable a la ejecución de sentencias extranjeras. Según el Tribunal, la ejecución de un fallo extranjero adoptada sin que existiera ninguna posibilidad de denunciar útilmente el carácter injusto del procedimiento que condujo a aquella, ya sea en el Estado de origen o en el Estado requerido, no puede considerarse compatible con el art. $6 \$ 1 \mathrm{CEDH}^{52}$. A continuación, observó que nunca hasta ahora había sido requerido para pronunciarse sobre el respeto de las garantías del procedimiento en el contexto del reconocimiento mutuo del derecho de la Unión Europea ${ }^{53}$ y añadió que siempre había aplicado el principio general, según el cual, un juez requerido de una solicitud de reconocimiento y ejecución de un fallo extranjero no

49 Reglamento (CE) núm. 44/2001 del Consejo, de 22 de diciembre de 2000, relativo a la competencia judicial, el reconocimiento y la ejecución de resoluciones judiciales en materia civil y mercantil, DO núm. L 12 de 16/01/2001, art. 34: «Las decisiones no se reconocerán: [...] 2) cuando se dictaren en rebeldía del demandado, si no se hubiere entregado al mismo la cédula de emplazamiento o documento equivalente de forma regular y con tiempo suficiente para que pudiera defenderse, a menos que no hubiere recurrido contra dicha resolución cuando hubiera podido hacerlo».

50 TEDH, Avotinš vs. Letonia [GS], $\$ 34$.

51 Una primera Sentencia de Sala de 25 de febrero de 2014 estableció por mayoría que no había existido violación del art. $6 \$ 1 \mathrm{CEDH}$.

52 TEDH, Avotiňš vs. Letonia [GS] [GS], $\$ 98$.

53 Ibid., $\$ 98$. 
podía darle cauce sin operar previamente un cierto control de la decisión en cuestión a la luz de las garantías de un proceso equitativo, pudiendo variar la intensidad de este control en función de las circunstancias.

Tras estos pasajes iniciales, el TEDH entró a considerar de forma muy detallada si se aplicaba la presunción Bosphorus al caso ${ }^{54}$. Sobre el ámbito de aplicación de la presunción, el TEDH confirmó los principios establecidos en su jurisprudencia anterior, de la que extrajo que la protección sustantiva de los derechos fundamentales en derecho de la Unión, en cuyo ordenamiento se enmarca el Reglamento Bruselas I, es salvo prueba en contrario equivalente al CEDH. Para alcanzar esta conclusión el TEDH tuvo especialmente en cuenta la existencia a día de hoy de la Carta de los Derechos Fundamentales (CDFUE), su valor jurídico primario reconocido por el Tratado de Lisboa y, en particular, su art. 52(3), que obliga a interpretar sus disposiciones de forma consistente con el CEDH. Por consiguiente, la condición más importante para la aplicación de la presunción se cumplía.

Como ya sabemos, dos condiciones adicionales debían cumplirse: en primer lugar, la ausencia de margen de discrecionalidad para las autoridades encargadas de aplicar la disposición del derecho de la Unión; y, en segundo lugar, que el mecanismo de control del respeto de los derechos fundamentales previsto en derecho de la Unión hubiese desplegado la integralidad de sus potencialidades, ofreciendo una protección equivalente al $\mathrm{CEDH}$.

En relación con la ausencia de discrecionalidad para el Estado miembro requerido, el TEDH evoca, en primer lugar, la naturaleza reglamentaria de la norma controvertida, que por definición es directamente aplicable en todos los Estados miembros en todos sus elementos ${ }^{55}$. No obstante, en la jurisprudencia del TEDH esta diferenciación no parece haber sido conclusiva. Puede recordarse en este sentido el asunto M. S. S. vs. Bélgica y Grecia, en el que aún tratándose del Reglamento de Dublín, el TEDH estimó que su art. 3 (2), que prevé la llamada cláusula de soberanía, en virtud de la cual, por derogación a la regla general inscrita en el art. 3(1), cualquier Estado miembro puede examinar una solicitud de asilo que le sea presentada, aun cuando este examen no le incumba en virtud de los criterios establecidos en ese Reglamento; de lo que dedujo que las autoridades belgas gozaban de discrecionalidad para no transferir el demandante si hubieran considerado que el país de destino no cumplía las condiciones a la luz del $\mathrm{CEDH}$, rechazando por consiguiente la aplicación de la protección equivalente a pesar de tratarse de un Reglamento ${ }^{56}$. O

54 Nada menos que diez páginas, el análisis más largo hasta la fecha, ibid., \$\$ 101-127.

55 TEDH, Avotinš vs. Letonia [GS], $\$ 106$.

56 TEDH, M. S. S. vs. Bélgica y Grecia, 340. 
recordemos, por otra parte, el asunto Biret vs. Francia ${ }^{57}$, en el que se debatía la ausencia de un proceso equitativo para una empresa que trató de desafiar la legalidad de dos directivas comunitarias que prohibían la importación de carne de vacuno tratada con hormonas, interdicción que contribuyó a su quiebra. El TEDH consideró que se trataba de un déficit de protección jurisdiccional ofrecida por la entonces CE y, en consecuencia, no atribuible a Francia; y a continuación aplicó la presunción de protección equivalente al no hallar una insuficiencia manifiesta ${ }^{58}$. Por consiguiente, aunque suele ocurrir que cuando los Estados miembros se encuentran sujetos sin ningún tipo de ambigüedad a mandatos muy específicos del derecho de la Unión que tienen que aplicar de forma directa, inmediata y clara (Reglamentos) el Estado miembro no goza apenas de margen de apreciación en su ejecución y el TEDH aplica la presunción de la protección equivalente como ocurrió en el mismo asunto Bosphorus, no creemos que sea el instrumento jurídico el dato definitivo, sino la concreta disposición de ese instrumento la que va a determinar si existe o no margen de discrecionalidad para el Estado miembro; puesto que a pesar de sus notables diferencias, a veces los Estados miembros carecen de margen real en la implementación de una directiva, mientras que pueden gozar de discrecionalidad a la hora de ejecutar un reglamento ${ }^{59}$.

A continuación, el TEDH centró su análisis en el art. 34 (2) del Reglamento Bruselas I afirmando que de acuerdo con la jurisprudencia del TJUE, los Estados miembros carecen de discrecionalidad en la ejecución de esta disposición ${ }^{60}$. Quizás se echa en falta un mayor grado de claridad en esta parte del fallo porque el TEDH no valora que el exequatur, según el Reglamento

57 TEDH, Biret vs. Estados miembros de la UE, núm. 13762/04, (Déc.) de 9 de diciembre de 2008, ECHR:2008:1209DEC001376204.

58 Más dudoso parece, sin embargo, el asunto TEDH, Cantoni vs. Francia [GS], Sentencia de 15 de noviembre de 1996, núm. 17862/91, ECHR:1996:1115JUD001786291, en el que se planteaba la responsabilidad de este Estado parte en un contexto en el que el ilícito de enmarcaba en la incorporación a su ordenamiento de una directiva comunitaria sobre la definición de los medicamentos. Si bien es cierto que la norma francesa de incorporación reproducía textualmente lo previsto en esa directiva, también lo es que la interpretación que hasta ese momento había realizado el Tribunal de Justicia de esa directiva otorgaba un amplio margen de discrecionalidad a los Estados miembros para que decidieran caso por caso qué debía entenderse por medicamento.

59 En un sentido parecido, Marta REQUEJO ISIDRO, «Avotiņš c. Letonia, Sentencia del TEDH, de 23 de mayo de 2016, as. 17502/07», op. cit., nota 2, p. 192.

60 TEDH, Avotinš̌ vs. Letonia [GS], $₫ 106$. 
de Bruselas I, lejos de ser automático ${ }^{61}$ cuenta con motivos que permiten denegarlo y, además, en la interpretación y aplicación de dichas causas la propia jurisprudencia del TJUE ha reconocido un margen de discrecionalidad a los tribunales requeridos ${ }^{62}$. Todo parece indicar que el modo en que el Tribunal Supremo de Letonia abordó esta cuestión al resolver el recurso no fue apropiado, pues se limitó a señalar que los argumentos del recurrente eran irrelevantes ante la constatación de la ausencia de recurso contra la Sentencia en origen, y ello a pesar de que habría tenido el deber de analizar con detenimiento los documentos obrantes en autos y de verificar la regularidad de las notificaciones practicadas en el proceso de origen con arreglo a sus propios parámetros, pasividad que parece a todas luces incompatible con las exigencias dimanantes del art. $6 \$ 1 \mathrm{CEDH}$. Por otra parte, si la carga de la prueba es la clave del fallo del

61 Véase, en este sentido, las apreciaciones de los jueces Ineta ZIEMELE, Ledi BIANKU y Vincent A. DE GAETANO en su voto particular a la Sentencia de la Sala del TEDH, dictada el 25 de febrero de 2014, y las consideraciones de Fernando GASCÓN INCHAUSTI, «El derecho procesal civil europeo comparece ante el Tribunal Europeo de Derechos Humanos...», op. cit., nota 2, p. 105.

62 Es cierto que las siguientes sentencias del TJUE podrían dar la impresión de que no existe discrecionalidad para los jueces nacionales a la hora de aplicar esta disposición del Reglamento sobre reconocimiento y ejecución de sentencias: de 16 de junio de 1981, Klomps vs. Michel, C-166/80, EU:C:1981:137; de 14 de diciembre de 2006, ASML, C-283/05, EU:C:2006:787; de 10 de octubre de 1996, Bernardus Hendrikman y Maria Feyen vs. Magenta Druck \& Verlag GmbH, C-78/95, EU:C:1996:380; de 28 de abril de 2009, Apostolides vs. Orams, C-420/07, EU:C:2009:271. Esta última insiste en que el art. 34.2 del Reglamento de Bruselas I impide la denegación del exequatur a favor de quien pudo recurrir la Sentencia y no lo hizo. Sin embargo, en los asuntos Gambazzi (STJCE de 2 de abril de 2009, C-394/07, EU:C:2009:219) y Trade Agency (STJUE de 6 de septiembre de 2012, C-619/10, EU:C:2012:531) el TJUE consideró que el órgano jurisdiccional requerido debía poder examinar la documentación obrante en el expediente para formarse su propia opinión acerca de si realmente hubo una adecuada notificación de la demanda o de la Sentencia y si, en definitiva, el demandado pudo ejercer su defensa en el Estado de origen. El Tribunal admitió que el juez requerido podía denegar el reconocimiento en virtud de la cláusula de orden público si tras una apreciación global del procedimiento y a la luz del conjunto de circunstancias pertinentes deducía que la resolución suponía un menoscabo manifiesto y desmesurado del derecho a un proceso equitativo debido a la imposibilidad de interponer un recurso efectivo en tiempo útil. Sin embargo, debe tratarse de inconsistencias manifiestas y desproporcionadas con el derecho a un proceso equitativo. Tanto en este último asunto como en el ASML Netherlands (STJCE de 14 de diciembre de 2006, C-283/05, EU:C:2006:787) el Tribunal interpretó de forma amplia la competencia de los tribunales internos para rechazar el reconocimiento en los supuestos de juicios en rebeldía. 
Tribunal Supremo de Letonia y este aspecto concreto no estaba regulado por el derecho europeo, podría fácilmente desprenderse que este tribunal gozaba de facto de un cierto grado de discrecionalidad, lo cual impediría la aplicación de la doctrina Bosphorus. Aparentemente, el Tribunal Supremo de Letonia podría haber cumplido con la obligación de reconocimiento que le imponía el Reglamento Bruselas I y con el art. 6 CEDH modificando la carga de la prueba. La falta de claridad de esta parte del fallo puede deberse a la opacidad del fallo del Tribunal Supremo de Letonia, que supuso tácitamente o bien que la carga de la prueba recaía sobre el demandante o que disponía de hecho de una posibilidad procesal de apelar el fallo chipriota ${ }^{63}$.

Nos preguntamos, de otro lado, qué suerte hubiese corrido este asunto de haber evocado el demandante ante el Tribunal Supremo de Letonia el art. 34 (1) del Reglamento Bruselas I —en la actualidad art. 45(1) a) del Reglamento Bruselas I bis-, según el cual, la solicitud de exequatur puede rechazarse si es manifiestamente contraria al orden público del Estado miembro requerido, lo cual otorgaría discrecionalidad a este último, imposibilitando la aplicación de la presunción. Esta cuestión fue evocada por el Centro AIRE como tercero interviniente, aunque fue rechazada por el TEDH por no haber sido alegada por el demandante ante el Tribunal Supremo de Letonia. Sin embargo, nos parece discutible que sea únicamente admisible su alegación a instancia de parte y no de oficio por parte del Tribunal nacional requerido cuando los derechos de la defensa han sido violados de forma manifiesta en el Estado de origen. De ser plausible la interpretación que proponemos, el Tribunal requerido habría cometido un error manifiesto de interpretación del derecho de la Unión que invalidaría la aplicación de la presunción ${ }^{64}$. Y la doctrina del Tribunal de Justicia en el asunto Trade Agency parece apuntar en este sentido ${ }^{65}$.

Más extenso fue el análisis de la segunda condición, el desarrollo de todas sus potencialidades por parte del mecanismo de supervisión unionista. Sobre

63 TEDH, Avotiņ̌̌ vs. Letonia [GS], $\$ 121$.

64 Ibid., $\$ \$ 94$ y 108. En la doctrina, Koen LENAERTS, "The Principle of Mutual Recognition in the Area of Freedom, Security and Justice», The Fourth Annual Sir Jeremy Lever Lecture, All Souls College Oxford, 30 de enero de 2015, p. 25, señala que en materia de cooperación civil los Estados miembros requeridos para el reconocimiento deben poder alegar la cláusula de orden público para evitar la ejecución cuando existen deficiencias sistémicas en el Estado miembro de origen que han provocado una infracción manifiesta de una norma considerada esencial para la Unión, https:// www.law.ox.ac.uk/sites/files/oxlaw/the_principle_of_mutual_recognition_in_the_ area_of_freedom_judge_lenaerts.pdf (consultado por última vez el 26 de octubre de 2016).

65 Véase supra nota 62. 
este particular, el TEDH otorga gran importancia a la función y las competencias del TJUE, incluso si el acceso del particular es netamente más restringido ${ }^{66}$. Resulta curioso observar que no fue decisivo para el TEDH que el Tribunal Supremo de Letonia no planteara una cuestión prejudicial al TJUE sobre la interpretación de las disposiciones más relevantes del Reglamento Bruselas I, señalando que esta segunda condición debía aplicarse sin excesivo formalismo y teniendo en cuenta las particularidades del mecanismo de control en cuestión. No tendría sentido, en opinión del TEDH, subordinar la aplicación de la presunción a la condición de que la jurisdicción nacional se dirija al TJUE en toda circunstancia sin excepción, incluso cuando ninguna cuestión real y seria se plantea en el asunto en cuanto a la protección de los derechos fundamentales por el derecho de la Unión o cuando el TJUE ya ha indiciado de manera precisa la interpretación que en materia de derechos fundamentales debe darse a la disposición de derecho de la Unión aplicable al caso ${ }^{67}$, lo que supone confirmar la plena convencionalidad de la doctrina del acto claro (acto claro, acto aclarado) del TJUE ${ }^{68}$, aspecto sobre el que ya se pronunció en el asunto Ullens de Schooten and Rezabek vs. Bélgica ${ }^{69}$. De todo ello el TEDH dedujo que también la condición del desarrollo de todas sus potencialidades por parte del mecanismo de supervisión unionista se cumplía en este asunto.

\section{LA EQUIVALENCIA DEL PRINCIPIO DE RECONOCIMIENTO MUTUO EN EL ESPACIO DE LIBERTAD, SEGURIDAD Y JUSTICIA}

La afirmación de la plena convencionalidad, salvo excepciones, del principio de reconocimiento mutuo en el marco del Reglamento Bruselas I es probablemente el desarrollo más importante del fallo del TEDH en el asunto Avotiņš vs. Letonia si tenemos en cuenta lo controvertido de esta cuestión. Recordemos en este sentido el análisis que desarrolló el TJUE en su Dictamen

${ }^{66}$ TEDH, Avotiņ̌s vs. Letonia [GS], $\$ 104$, Bosphorus vs. Irlanda, $\$ \$ 160-165$; y Michaud vs. Francia, $\$ \$ 106-111$.

67 TEDH, Avotinš vs. Letonia [GS], \$109.

68 STJCE Cilfit y otros, 283/81, EU:C:1982:335; STJCE Intermodal Transports, C-495/03, EU:C:2005:552; STJUE Consiglio nazionale dei geologi y Autorità garante della concorrenza e del mercato, C-136/12, EU:C:2013:489; STJUE Ferreira da Silva, C-160/14, EU:C:2015:565. Sobre el tema puede verse SILVEIRA, A., PEREZ FERNANDES, S., «Preliminary References, Effective Judicial Protection and State Liability. What if the Ferreira da Silva Judgment Had not Been Delivered?», Revista de Derecho Comunitario Europeo, núm. 54, 2016, pp. 631-666.

69 TEDH, Ullens de Schooten and Rezabek vs. Bélgica, núm. 3989 y 38353/07, (déc.) de 20 de septiembre de 2011, ECHR:2011:0920JUD000398907. 
núm. 2/13 sobre la adhesión de la Unión al CEDH de su propio monopolio jurisdiccional, el cual parecía dirigido a sustraer del escrutinio del Tribunal de Estrasburgo determinados capítulos del acervo comunitario. Así parecía deducirse del énfasis sobre la salvaguarda de la confianza mutua, donde el TJUE reiteró la idea, según la cual, las materias que han sido objeto de un traspaso de competencias a la Unión, las relaciones mutuas entre los Estados miembros debían regirse por el derecho de la Unión, con exclusión, si así lo exige éste, de cualquier otro derecho.

Sin embargo, el fallo que comentamos, dotado de un alto grado de persuasión y deferencia, será recordado probablemente por su contribución a relajar esta tensión, en particular cuando el TEDH destaca la importancia de los mecanismos de reconocimiento mutuo para la construcción del ELSJ ${ }^{70}$, aunque añadiendo que sus modalidades de creación no pueden chocar con los derechos fundamentales, límite además confirmado por el art. 67 (1) $\mathrm{TFUE}^{71}$. A continuación, añadió un comentario crítico al Dictamen TJUE núm. 2/13, en particular, cuando a propósito de los instrumentos del ELSJ basados en el principio de reconocimiento mutuo el TJUE limitó únicamente a casos excepcionales el control por el Estado miembro requerido del respeto de los derechos fundamentales por el Estado miembro de origen ${ }^{72}$. Para el TEDH, limitar ese control únicamente a casos excepcionales podría, en situaciones concretas, ir al encuentro de la obligación que impone el CEDH de permitir al juez del Estado requerido de proceder a un control adaptado a la gravedad de las alegaciones serias de violación de derechos en el Estado de origen a fin de evitar una insuficiencia manifiesta en su protección ${ }^{73}$. Y ello porque presumir esta observancia implica privar a los tribunales internos de discrecionalidad en estos asuntos, lo cual paradójicamente conduce a una aplicación automática de la presunción Bosphorus ${ }^{74}$. Según el TEDH, a pesar de las aparentes limitaciones para los tribunales internos cuando el principio de confianza mutua está en juego, el CEDH les exige que no existan deficiencias manifiestas en la protección del $\mathrm{CEDH}^{75}$.

Centrándose a continuación en el Reglamento Bruselas I, el TEDH afirmó que el sistema unionista de reconocimiento mutuo establecido en este

\footnotetext{
Ibid., $\$ 113$.

Ibid., $\$ 114$.

Ibid., $\$ 114$, Dictamen TJUE núm. 2/13, apartado 192.

73 Sobre la necesidad de que exista un estándar mínimo de control en relación con la protección del art. 6 CEDH puede verse, entre otros, Louwrens Rienk KIESTRA, The Impact of European Convention on Human Rights on Private International Law, T.M.C. Asser Press, The Hague, 2014, pp. 254 y ss.

74 TEDH, Avotinšs vs. Letonia [GS], $\$ 115$.

75 Ibid., $\$ 116$.
} 
instrumento era de forma general compatible con el art. $6 \mathrm{CEDH}^{76}$, aunque mostró cierto escepticismo en cuanto a la interpretación y aplicación que había realizado el Tribunal Supremo de Letonia para el reconocimiento de la Sentencia chipriota, dejando entrever que este reconocimiento debería haberse rechazado. Según el TEDH, el demandante había planteado ante los tribunales letones argumentos convincentes sobre los vicios procesales de los que en su opinión adolecía la Sentencia chipriota, los cuales eran contrarios al art. 6 CEDH e impedían, por tanto, su ejecución en Letonia ${ }^{77}$. Además, el TEDH estimó que el Tribunal Supremo de Letonia aplicó demasiado mecánicamente las disposiciones del Reglamento Bruselas I que establecen excepciones al reconocimiento automático, extraña forma de actuar si tenemos en cuenta que la jurisprudencia del TJUE sobre el art. 34(2) del Reglamento se muestra bastante proclive a la salvaguarda de los derechos de la defensa ${ }^{78}$. Refiriéndose, en particular, al art. 34 (2) Reglamento Bruselas I y a la carga de la prueba, materia que no queda regulada por el derecho de la Unión, el TEDH consideró que podría constituir una insuficiencia manifiesta de los derechos de la defensa, aunque rechazó que en las circunstancias particulares de este asunto este hubiese sido el caso, incluso si la aplicación del Reglamento que realizó el Tribunal Supremo de Letonia fue lamentable ${ }^{79}$.

Por consiguiente, el TEDH halló claramente una deficiencia manifiesta en la protección del CEDH, aunque fueron los hechos concretos del asunto Avotings los que le llevaron a eximir de responsabilidad el Estado parte demandado. Y ello porque de acuerdo con el derecho chipriota, el Sr. Avotiňš tuvo a su disposición una oportunidad procesal de apelar el fallo ante aquella jurisdicción $^{80}$. Que no fuera conciente de esta oportunidad poco importaba porque al haber concluido un contrato de préstamo debería haberse familiarizado con las consecuencias jurídicas del reconocimiento de deuda que él mismo había firmado y las concretas modalidades de un eventual procedimiento ante las jurisdicciones chipriotas. Por el contrario, su inacción y su falta de diligencia le llevaron en gran medida a crear la situación de la que se quejaba ante el $\mathrm{TEDH}$, la cual podría haber evitado para no sufrir ningún perjuicio ${ }^{81}$. Como consecuencia de todo ello, el TEDH concluyó que en las circunstancias del presente asunto no había existido una protección deficiente del $\mathrm{CEDH}^{82}$.

\footnotetext{
Ibid., \$\$ 117-119.

Ibid., $\$ 120$.

78 Supra, nota 62.

79 TEDH, Avotinšs vs. Letonia [GS], \$ 121.

$80 \quad$ Ibid., $\$ 122$.

81 Ibid., $\$ 124$.

82 Ibid., $\$ 125$.
} 


\section{AVOTIN,Š, EL STATU QUO Y EL LARGO CAMINO HACIA LA ADHESION DE LA UNIÓN AL CEDH}

Por paradójico que parezca, en un asunto como Avotinšs vs. Letonia la adhesión habría reportado mayores ventajas para salvaguardar la autonomía del derecho de la Unión — como el TJUE pareció preservar a toda costa en su Dictamen núm. 2/13 - que el statu quo, es decir, el examen de la convencionalidad del derecho de la Unión por la intermediación de sus Estados miembros.

Comencemos por la doctrina Bosphorus. Para aplicar los criterios exigidos en la presunción de equivalencia, el TEDH debe apreciar si la acción u omisión reprochada al Estado parte le viene impuesta por el derecho de la Unión, rechazando la aplicación de la presunción si este no es el caso. Recordemos a propósito del Reglamento de Dublín, el fallo del TEDH en el asunto M. S. S. vs. Bélgica y Grecia $^{83}$ y del TJUE en el asunto $N$. $S^{84}$. El análisis desarrollado por cada una de estas jurisdicciones reposó sobre bases radicalmente distintas. El TEDH analizó si el Reglamento de Dublín acordaba a los Estados miembros una potestad discrecional para examinar ellos mismos las solicitudes de asilo si lo consideraban lícito conforme al Reglamento, lo que le llevó a rechazar la aplicación de la doctrina Boshorus; mientras que el TJUE situó el Reglamento de Dublín en el marco de la confianza mutua y, desde esta perspectiva, solo permitió a los Estados miembros examinar ellos mismos las solicitudes de asilo si existían riesgos sistémicos en el Estado miembro de origen. De forma similar, en el asunto Michaud vs. Francia el TEDH tuvo que examinar hasta que punto era obligatorio para el Consejo de Estado francés el planteamiento de una cuestión prejudicial. Y en el asunto que venimos considerando tuvo que interpretar el art. 34 (1) del Reglamento Bruselas I. En todas estas situaciones, el TEDH valora libremente el ámbito de aplicación del derecho de la Unión a fin de determinar si controlará o no la convencionalidad de la medida nacional de ejecución. No hace falta resaltar las ventajas para preservar la autonomía del derecho de la Unión que en este tipo de procedimientos habrían reportado el sistema del codefensor o las disposiciones sobre la intervención previa del TJUE previstas en el proyecto de adhesión ${ }^{85}$. Cualquiera de ellas permitiría que fuera la propia Unión -y no el TEDH - quien explicara qué se enmarca en la competencia de cada sujeto. Por el contrario, la imposibilidad de llevar a cabo esta empresa obliga al TEDH a interpretar de forma autónoma el Reglamento Bruselas I, no solo

\footnotetext{
83 TEDH, M. S. S. vs. Grecia y Bélgica.

84 STJUE (GS) de 21 de diciembre de 2011, C-411 y 493/10, EU:C:2011:865.

85 Doc. núm. 47+1(2013)008 Rev2 (en lo sucesivo, Proyecto de Acuerdo).
} 
en el asunto Avotiņš vs. Letonia, sino también en un fallo reciente en el que el TEDH interpreta este Reglamento junto con la Directiva sobre los servicios audiovisuales ${ }^{86}$ en un contexto en el que los órganos jurisdiccionales nacionales rechazaron plantear una cuestión prejudicial ${ }^{87}$. Es cierto que el TEDH cita adecuadamente la jurisprudencia del TJUE sobre estas normas, pero da su propia interpretación. No cabe duda que el sistema de intervención previa del TJUE que preveía el proyecto de adhesión para proteger el monopolio interpretativo del TJUE solventaría este problema. Por lo que se refiere al asunto Avotinš̌ vs. Letonia, esta intervención previa del TJUE habría permitido saber si el órgano jurisdiccional requerido debería haber verificado la regularidad de las notificaciones practicadas en el proceso de origen ${ }^{88}$ o haber planteado de oficio la cláusula de orden público del art. 34 (1) del Reglamento Bruselas $I^{89}$, cuestión fundamental que de haber recibido una respuesta positiva habría impedido la aplicación de la presunción de equivalencia. Por el contrario, a falta de adhesión y salvo error manifiesto por parte del juez nacional, es la interpretación dada por este último la que será tomada en consideración en Estrasburgo. Si bien es cierto que el TJUE podría obviar el fallo por no ser oponible a la Unión al no ser aún parte en el procedimiento, será tenido muy en cuenta por los Estados parte y por sus órganos jurisdiccionales, lo que será susceptible de crear los problemas que ya se manifestaron en la Unión con la ejecución del fallo del TEDH en el asunto Matthews vs. Reino Unido ${ }^{90}$.

Abordemos a continuación el principio de reconocimiento mutuo en el ELSJ. Es interesante observar que la mayoría de las objeciones planteadas por el TJUE en su Dictamen núm. 2/13 a la jurisdicción del TEDH hacen referencia a situaciones que ya son objeto a día de hoy de examen de convencionalidad por la jurisdicción de Estrasburgo. En efecto, el TEDH ya impone algunas obligaciones a los Estados miembros sobre el ejercicio de potestades

86 Directiva (EU) núm. 2010/13, DO núm. L 95/1.

87 TEDH, Arlewin vs. Suecia, núm. 22302/10, Sentencia de 1 de marzo de 2016, ECHR:2016:0301JUD002230210.

88 Supra, nota 62.

89 Ibid.

90 Como se recordará, la firme oposición de nuestro país por la siempre controvertida cuestión territorial impidió la aprobación de la reforma del Acta de 1976 sobre la elección de los representantes al Parlamento Europeo por sufragio universal directo. Frente a ello, el Reino Unido decidió ejecutar unilateralmente el fallo y nuestro país presentó un recurso por incumplimiento. El TJCE interpretó el derecho originario, es decir, el acta de conformidad con el fallo del TEDH, STJCE de 12 de septiembre de 2006, España vs. Reino Unido, C-145/04, EU:C:2006:543. 
discrecionales frente a los solicitantes de asilo ${ }^{91}$ Y tratándose de potestades regladas, el TEDH también ha ejercido esta jurisdicción frente a los Estados miembros en temas de cooperación judicial ${ }^{92}$ o de responsabilidad parental ${ }^{93}$. Ahora bien, los diversos esquemas de reconocimiento mutuo permiten una diferente invocación de los derechos fundamentales como fundamento para no ejecutar el acto. Así, mientras que en relación con el reconocimiento y la ejecución de sentencias civiles los derechos fundamentales pueden ser invocados en el marco de la cláusula de orden publico o en el marco de cualquier otra excepción, implicando que el exequátur, lejos de ser automático, cuenta con motivos que permiten denegarlo; la jurisprudencia del TJUE parece hasta ahora más restrictiva en relación con la Orden Europea de Detención, con el Sistema de Dublín o con el Reglamento de Bruselas II sobre la responsabilidad parental en relación con las órdenes de retorno. Quizás por ello algunos autores han afirmado que la adhesión de la Unión al CEDH crearía problemas insolubles en relación con el principio de reconocimiento mutuo ${ }^{94}$.

Nos preguntamos, sin embargo, si ello sería necesariamente así porque desde una exclusiva perspectiva del derecho de la Unión, el reconocimiento mutuo no es más que un principio dirigido a facilitar la cooperación judicial entre los Estados miembros, que no debería prevalecer sobre la obligación jurídica primaria de respetar los derechos fundamentales, componente clave del ELSJ como prevé expresamente el art. 67 (1) TFUE. En este sentido, el propio TJUE ha dado preferencia en muchos asuntos a estos últimos. Recordemos en este sentido el asunto $N$. S., en el que el TJUE dio preferencia a la obligación de evitar tratos inhumanos en el sentido del art. 4 CDFUE, frente al cumplimiento de las disposiciones del Reglamento de Dublín cuando existieran deficiencias sistémicas en el procedimiento de asilo y en las condiciones de recepción en el Estados miembro de origen ${ }^{95}$. En sus conclusiones en el asunto Radu, que trataba sobre los motivos de no ejecución de una orden de detención europea, el abogado general Sharpston afirmó que la autoridad judicial competente del Estado miembro de ejecución podía denegar la solicitud

91 TEDH, M. S. S. vs. Bélgica y Grecia; Tarakhel vs. Suiza; Sharifi y otros vs. Italia, Sentencia de 21 de octubre de 2014, núm. 16643/09, ECHR:2014:1021JUD001664309.

92 TEDH, Avotinšs vs. Letonia [GS].

93 TEDH, Povse vs. Austria.

94 Alexander KORNEZOV, «The forthcoming EU accession to the ECHR: a Myriad of Problems, few Solutions», CELS lunchtime Seminar Series, 7, 2012, http://www.sms. cam.ac.uk/media/1341997 (consultado por última vez el 26 de octubre de 2016); Cathryn COSTELLO, "Courting Access to Asylum in Europe: Recent Supranational Jurisprudence Explored», Human Rights Law Review, vol. 12, núm. 2 (2012), pp. 287-339.

STJUE $N$. S., apartado 94. 
de entrega cuando se ponga de manifiesto que los derechos humanos de la persona cuya entrega se solicita han sido vulnerados ${ }^{96}$. Desafortunadamente, el TJUE dio respuestas muy sucintas a las serias cuestiones que planteaba el órgano jurisdiccional $a$ quo, de lo que parecía extraerse que únicamente los motivos que aparecen reflejados en los arts. 3 y 4 de la Decisión Marco podrían constituir fundamentos válidos de no ejecución.

Sin embargo, un fallo reciente como es el recaído en los asuntos acumulados Pál Aranyosi y Robert Căldăraru ${ }^{97}$ parece dotar la doctrina del TJUE de una mayor flexibilidad, al admitir que cuando la autoridad judicial del Estado miembro de ejecución de una orden europea de detención disponga de elementos de los que se deduzca un riesgo real de tratos inhumanos o degradantes del detenido en el Estado miembro de emisión, esa jurisdicción está obligada a apreciar la existencia de ese riesgo cuando debe decidir la entrega, denegándose en caso de confirmación ${ }^{98}$. De un tenor similar, es el fallo recaído recientemente en el asunto Petruhhin ${ }^{99}$, que versaba sobre una solicitud de extradición cursada por la Federación de Rusia ante Letonia en relación con un nacional estonio detenido en el territorio de ese Estado miembro. El TJUE señaló que en la medida en que la autoridad requerida disponga de elementos que acrediten un riesgo real de que se inflija un trato inhumano o degradante deberá apreciar la existencia de este riesgo a la hora de pronunciarse sobre la extradición ${ }^{100}$.

Como puede verse, el TJUE se aproxima en estos fallos sobre la interpretación de la orden europea de detención a la posición intersistémica bastante más flexible adoptada, no ya solo por el TEDH, sino también por algunas jurisdicciones nacionales cuyos fallos expondremos en el apartado siguiente;

96 EU:C:2012:648, apartado 97.

97 STJUE(GS) de 5 de abril de 2016, Aranyosi y Căldäraru, C-404 y 659/15 PPU, EU:C:2016:198. Sobre este interesante fallo puede verse en este mismo volumen, Pablo MARTÍN RODRÍGUEZ, «La emergencia de los límites constitucionales de la confianza mutua en el Espacio de Libertad, Seguridad y Justicia en la Sentencia del Tribunal de Justicia Aranyosi y Căldăraru».

98 STJUE(GS) Aranyosi y Căldăraru, apartados 85-88 y 98.

99 STJUE(GS) de 6 de septiembre de 2016, Petruhhin, C-182/15, ECLI:EU:C:2016: 630.

$100 \mathrm{Ibid}$., apartado 59. Puede verse, asimismo, STJUE de 24 de mayo de 2016, Dworzecki, C-108/16 PPU, EU:C:2016:346; en el que el TJUE otorga una protección amplia del derecho a un proceso equitativo de una persona citada a comparecer ante un tribunal, incluso superando el estándar del $\mathrm{CEDH}$, cuya jurisprudencia exige únicamente que el acusado haya tenido un conocimiento suficiente de la acusación penal, TEDH, Sejdovic vs. Italia, Sentencia de 1 de marzo de 2006, ECHR:2006:0301JUD005658100. 
mientras que parece alejarse de su categórico enfoque en el Dictamen núm. 2/13. Y podría esperarse que lo extienda a las restantes áreas del ELSJ en las que se aplica el principio de reconocimiento mutuo, en particular, el Reglamento de Dublín sobre el asilo y el Reglamento Bruselas II Bis sobre el reconocimiento y la ejecución de resoluciones judiciales en materia matrimonial y de responsabilidad parental ${ }^{101}$, tanto más si tenemos en cuenta que el grado

${ }^{101} \mathrm{La}$ confrontación entre el art. $8 \mathrm{CEDH}$ sobre el respeto a la vida familiar y el Reglamento Bruselas II Bis parece no ser a veces del todo pacífica en los supuestos de sustracción de menores tras la ruptura sentimental de una pareja. Estas situaciones dan lugar a la aplicación del Convenio de La Haya de 1980 sobre los aspectos civiles de la sustracción internacional de menores y/o el Reglamento Bruselas II Bis (Reglamento (CE) núm. 2201/2003), normas que concretizan el principio de retorno inmediato del menor sustraído. Suele ocurrir, sin embargo, que esta ejecución inmediata se retrasa a veces. Véase, por ejemplo, la problemática planteada en el asunto TEDH, Serghides vs. Polonia, núm. 31515/04, (déc.) de 2 de noviembre de 2010, ECHR:2010:1102JUD003151504. Si en semejantes circunstancias hay indicios serios de que el retorno podría conllevar un riesgo serio para el menor, el art. $8 \mathrm{CEDH}$ obligaría al juez nacional a desautorizarlo, TEDH, Neulinger y Shuruk vs. Suiza [GS], núm. 41615/07, Sentencia de 6 de julio de 2010, ECHR:2010:0706JUD004161507; TEDH, Sneersone y Kampanella vs. Italia, núm. 14737/09, Sentencia de 12 de julio de 2011, ECHR:2011:0712JUD001473709; TEDH, X./Letonia, núm. 27853/09, Decisión de 13 de diciembre de 2011, ECHR:2013:1126JUD002785309; TEDH, M. R. y L. R. vs. Estonia, núm. 13420/12, Decisión de 15 de mayo de 2012, ECHR:2013:1126JUD002785309; TEDH, B. vs. Bélgica, núm. 4320/11, Decisión de 10 de julio de 2012, ECHR:2012:0710JUD000432011. Este enfoque del TEDH contrasta con algún fallo del TJUE, que parece privilegiar el principio de reconocimiento mutuo sobre la protección de los derechos fundamentales, Véase, en este sentido, STJUE de 1 de julio de 2010, Povse, C-211/10 PPU, EU:C:2010:400; y de 22 de diciembre de 2010, Zárraga, C-491/10 PPU, EU:C:2010:828; en los que consideró que en el Estado miembro de ejecución la orden de retorno no podía denegarse ni siquiera si existía un grave menoscabo del interés superior del menor, pudiendo sólo invocarse ante el órgano jurisdiccional competente del Estado miembro de origen a través de una eventual demanda de suspensión de la ejecución. Es cierto, sin embargo, que en otros asuntos el juez comunitario desarrolla un impecable examen de convencionalidad, por ejemplo, STJUE de 5 de octubre de 2010, J. McB. vs. L. E., C-400/10 PPU, EU:C:2010:582, apdo. 53. Sin embargo, en contraste con el asunto Povse, el TJUE tiene en cuenta el art. 52(3) CDFUE y cita la jurisprudencia del TEDH. Con todo, la posible incongruencia — de existir — suele ser salvada por el TEDH apoyándose en la presunción de equivalencia como ocurrió en el asunto TEDH, Povse vs. Austria. En efecto, en ejecución de la Sentencia prejudicial, el juez austriaco denegó la suspensión del retorno del menor. Presentado recurso contra Austria ante el TEDH por violación 
de automaticidad del reconocimiento mutuo en estos distintos instrumentos no es uniforme ${ }^{102}$, lo que parece llamar a las instituciones a dotarlos de homogeneidad.

Hasta que ello ocurra, estos fallos recientes del TJUE parecen dejar fuera de duda varias cosas. En primer lugar, confirman el papel del TJUE como un verdadero componedor en materia de derechos fundamentales. Desde la perspectiva del CEDH sería ideal que los siguientes desarrollos jurisprudenciales confirmaran esta flexibilidad hasta el punto de que el TJUE llegue incluso a relativizar su objeción relacionada con el ELSJ en el Dictamen núm. 2/13 y su progenie la doctrina Melloni, la cual no parece ser especialmente persuasiva. En efecto, los Estados miembros podrían, en ciertas circunstancias, encontrarse bajo la obligación de no aplicar estándares de protección más elevados que el nivel armonizado en la CDFUE, pero ésta última no puede conferir un nivel de protección inferior al estándar mínimo establecido por el TEDH. Por consiguiente, mientras que es cierto que los Estados miembros podrían de forma teórica otorgar un nivel de protección más generoso como una facultad dimanante del art. $53 \mathrm{CEDH}$, no podrían ejercer esa facultad en virtud de la primacía del derecho de la Unión en aquellas disposiciones de la CDFUE cuyo estándar de protección haya sido armonizado siempre que este no sea inferior al CEDH.

del art. 8 CEDH, el TEDH se limitó a aplicar la presunción de equivalencia, considerando que las autoridades austriacas se habían limitado a aplicar la Sentencia prejudicial del TJUE. Frente a la interesante alegación de que el TJUE no había realizado en realidad un análisis de la confrontación con el art. $8 \mathrm{CEDH}$, el TEDH se limita a afirmar: «It follows that the present case differs from the Bosphorus case in that the CJEU was not required to rule on the alleged violation of the applicants' fundamental rights. However, the CJEU made it clear that within the framework of the Brussels IIa Regulation it was for the Italian courts to protect the fundamental rights of the parties involved. Consequently, the applicants' rights have to be asserted before the Italian courts.»

102 Así, por ejemplo, el reconocimiento mutuo parece dejar más espacio a la protección de los derechos fundamentales en los ámbitos regidos por el Reglamento Bruselas I. Véase, por ejemplo, la Sentencia ya citada en el asunto Trade Agency Ltd vs. Seramico Investments Ltd. Por otra parte, la Directiva 2014/41/CE del Parlamento Europeo y del Consejo, de 3 de abril de 2014, relativa a la orden europea de investigación en materia penal (DO núm. L 130, de 1 de mayo de 2014) contiene en su art. 11 (1f) un motivo de rechazo cuando existan motivos fundados para creer que la ejecución de la medida de investigación indicada en la orden europea sería incompatible con las obligaciones del Estado miembro de ejecución de conformidad con el art. 6 TUE y la Carta. Puede verse, asimismo, el considerando 19 de esta Directiva. 
Y una lectura no menos integradora podría hacerse del fallo del TEDH en el asunto Tarakhel vs. Suiza, incluso si ha sido expuesto como paradigma de contradicción entre Estrasburgo y Luxemburgo. Como se recordará, el TJUE señaló en el asunto $N$. S. que el reenvío del solicitante de asilo al Estado miembro de entrada a la Unión en aplicación del Reglamento de Dublín debía efectuarse sin verificación suplementaria del respeto de los Derechos fundamentales, salvo fallo sistémico en aquel país; mientras que en el asunto Tarakhel vs. Suiza el TEDH no se contentó con retener el fallo sistémico, sino que exigió un examen individualizado de la situación de cada demandante ${ }^{103}$. Pero los hechos en este último asunto fueron determinantes para que el TEDH exigiera el examen individualizado, al tratarse de un padre con seis hijos el que solicitaba no ser trasladado a Italia. Poco tiempo después, en el asunto A.M.E.vs. Países Bajos ${ }^{104}$, sobre un somalí solicitante de asilo que alegó que si era trasladado a Italia corría el riesgo de sufrir tratos inhumanos o degradantes, el TEDH observó que a diferencia de Tarakhel, en este asunto el demandante no tenía menores a su cargo y que la situación para los solicitantes de asilo en Italia no podría ser en ningún caso equiparada a la de Grecia en el asunto M. S. S. vs. Bélgica y Grecia, añadiendo que en caso de dificultades, las autoridades italianas podrían reaccionar de manera apropiada. Por tanto, aquel paradigma de la contradicción no parece ser sino una doctrina aislada, cuya peculiaridad reside en sus hechos.

Todo ello nos lleva a pensar que la exigencia del TJUE en el Dictamen núm. 2/13 sobre la necesidad de que el proyecto de adhesión cuente con una cláusula de coordinación entre los arts. $53 \mathrm{CEDH}$ y 53 CDFUE no debería ser absolutamente inamovible. Ya expusimos en otro trabajo la inviabilidad tanto de una reserva - que por su alcance no podría ser sino general y como tal prohibida por el CEDH - como de una cláusula de desconexión ${ }^{105}$. Una interesante opción alternativa ha sido realizada recientemente por el Comité MEIJERS para introducir en este proyecto una cláusula sobre confianza mutua. En

103 TEDH, Tarakhel vs. Suiza [GS], núm. 29217/12, Sentencia de 4 de noviembre de 2014, ECHR:2014:1104JUD002921712, \$122: «Puede desprenderse que si los demandantes hubiesen sido reenviados a Italia sin que las autoridades suizas hubiesen obtenido previamente de las autoridades italianas una garantía individual en relación con la recepción adaptada, de una parte, a la edad de los niños, y, de otra, a la preservación de la unidad familial, habría violación del art. 3 del Convenio».

104 TEDH, A.M.E. vs. Países Bajos, núm. 51428/10, Sentencia de 13 de enero de 2015 ECHR:2015:0113DEC005142810.

105 José Manuel CORTÉS MARTÍN, «Autonomía versus sumisión ...», op. cit.,nota 12, pp. 27-50. 
opinión de este grupo de expertos, su renegociación debería permitir un equilibrio entre el principio de confianza mutua y la posibilidad para los jueces nacionales de comprobar en situaciones excepcionales la observancia de los derechos fundamentales en casos individuales y para ello proponen una cláusula del siguiente tenor: "Cuando ejecuten el derecho de la Unión, los Estados miembros pueden ser requeridos en virtud de este Derecho para presumir que han sido respetados los Derechos fundamentales en los demás Estados miembros. No obstante, permanecen obligados a rechazar la cooperación con otro Estado miembro prevista en el instrumento que prevé el reconocimiento mutuo si existen fundamentos sustanciales para creer que dicha cooperación daría lugar a una seria violación de los Derechos fundamentales tal como se protegen en el $\mathrm{CEDH}$ y sus protocolos» ${ }^{106}$. He aquí un tertium genus entre las jurisprudencias de ambos tribunales, aunque su viabilidad dependerá de que sea aceptada por los demás Estados parte en el CEDH. Pero incluso si no es aceptada, un fallo como el recaído en el asunto Avotinš vs. Letonia parece demostrar una suficiente coordinación y toma en consideración de las peculiaridades del ELSJ.

Se trata, sin duda, de una de las cuestiones más delicadas de la adhesión de la Unión al CEDH porque no se basa en aspectos estructurales o institucionales, sino en una divergencia de jurisprudencias entre el TJUE y el TEDH, la cual tiene su origen probablemente en las diferentes funciones que ambas jurisdicciones tienen encomendadas. Por su propia función, difícilmente se puede impedir al TEDH que examine una queja planteada por una víctima solo porque debe presumirse que el Estado miembro respeta los derechos fundamentales. Por su parte, el TJUE no se pronuncia sobre los hechos particulares de un asunto, sino que se limita a interpretar el derecho de la Unión en relación con los derechos fundamentales. Por consiguiente, mientras que el Tribunal de Estrasburgo da una respuesta concreta a un asunto preciso, el Tribunal de Luxemburgo da una respuesta abstracta a una cuestión de interpretación planteada por un órgano jurisdiccional nacional. Así, en el marco de la cooperación judicial europea y pese a estas diferentes misiones, el TEDH no ve obstáculo alguno al reconocimiento y ejecución de un fallo por los tribunales de un Estado miembro dictado por los tribunales de otro siempre que el demandante se haya beneficiado en ese Estado del conjunto de garantías jurisdiccionales previstas en el $\mathrm{CEDH}^{107}$.

106 Véase Note on Mutual Trust and Opinion 2 vs. 13 on Accession of the European Union to the European Convention on Human Rights, Standing Committee of Experts on International Immigration, Refugee and Criminal Law, abril de 2015, http://www. statewatch.org/news/2016/apr/eu-meijers-cttee-eu-echr.pdf (consultado por última vez el 26 de octubre de 2016).

107 Véase, por ejemplo, del TEDH la decisión sobre la admisibilidad en el asunto Povse vs. Austria. 
En cuanto al asilo, el problema parece residir en la diferente perspectiva con la que cada una de estas jurisdicciones aborda la cuestión y cuya solución no parece encontrarse sino en un acercamiento de doctrinas. La situación parece haber evolucionado tras el fallo del TJUE en el asunto $N$. S. Mientras que el TJUE solo admitía rechazar el reconocimiento mutuo ante la existencia constatada de un fallo sistémico, en el Dictamen núm. 2/13 se limitó a señalar que podría hacerse en supuestos excepcionales ${ }^{108}$. En un fallo reciente, el TJUE recuerda su doctrina sobre las circunstancias excepcionales, pero añade que incluso en presencia de estas circunstancias el órgano jurisdiccional nacional debe verificar si existe una violación del art. 4 CDFUE que prohíbe los tratos inhumanos o degradantes ${ }^{109}$. Por consiguiente, la brecha entre ambas jurisprudencias no parece ser insalvable. Hasta que alguna solución se encuentre, lo que el asunto Avotiňš vs. Letonia parece poner de manifiesto es que sin adhesión el ELSJ ya es objeto de escrutinio por parte del TEDH. El desafío a la propia concepción de la confianza mutua difícilmente llegará a ser más severa en Estrasburgo de lo que ya lo es a día de hoy, sin que la Unión sea parte en el proceso para defender su propia concepción, limitándose a una mera tercera intervención, y sin que el TJUE pueda arrojar su propia interpretación de la norma controvertida en caso de que aún no exista. Por el contrario, la adhesión facilitaría un escrutinio externo del ELSJ con la participación activa de sus protagonistas, lo cual podría permitir — pensamos — una mejor evaluación tanto de estos instrumentos basados en el principio de reconocimiento mutuo como de la protección de los derechos fundamentales de los particulares afectados ${ }^{110}$.

108 Dictamen TJUE núm. 2/13, apartados 191-192.

109 Véase la posición más flexible del TJUE en el asunto C-455/15 PPU, P. vs. G., STJUE de 19 de noviembre de 2015, EU:C:2015:763, apartado 53: «[...] cuando no exista una violación manifiesta, habida cuenta del interés superior del menor, de una norma jurídica considerada esencial en el ordenamiento jurídico de un Estado miembro o de un derecho reconocido como fundamental en ese ordenamiento jurídico, dicha disposición no permite al órgano jurisdiccional de ese Estado miembro que se considera competente para resolver sobre la custodia de un menor denegar el reconocimiento de la resolución de un órgano jurisdiccional de otro Estado miembro que ha resuelto sobre la custodia de dicho menor.»

${ }^{110}$ Véase, en este sentido, Steve PEERS, The ECJ and the EU's accession to the ECHR: a clear and present danger to human rights protection, en http://eulawanalysis.blogspot. com.es/2014/12/the-cjeu-and-eus-accession-to-echr.html; Jörg POLAKIEWICZ, Accession to the European Convention on Human Rights (ECHR): Stocktaking after the ECJ's Opinion and Way Forward, Parlamento Europeo, Audiencia Pública, Comisión de asuntos constitucionales, 20 de abril de 2016, http://www.europarl.europa.eu/ 


\section{EL PRINCIPIO DE RECONOCIMIENTO MUTUO Y LAS JURISDICCIONES SUPREMAS NACIONALES: ¿UNA INCIPIENTE INSURRECIÓN?}

Tratando sobre el principio de reconocimiento mutuo, ya sabemos que en el Dictamen núm. 2/13 el TJUE estableció un particular enfoque intersistémico al afirmar que en virtud del principio de confianza mutua, los Estados miembros pueden verse obligados a considerar, salvo circunstancias excepcionales, que todos los demás respetan el derecho de la Unión, y, muy especialmente, los derechos fundamentales reconocidos por ese derecho ${ }^{111}$. Aunque todo dependerá de qué se entienda por casos excepcionales, esta exclusión automática o, todo lo más, limitada a esos supuestos, de la competencia del juez requerido para examinar si se respetan los derechos y libertades protegidos en la CDFUE y en el CEDH es cuanto menos problemática a la luz de la jurisprudencia de Estrasburgo y ha sido objeto de críticas no solo por la doctrina ${ }^{112}$, sino también por el Parlamento Europeo ${ }^{113}$ y por algunas jurisdicciones supremas de los Estados miembros.

committees/en/afco/events-hearings.html?id=20160420CHE00201 (webs consultadas por última vez el 26 de octubre de 2016).

111 Véase, en este sentido, Dictamen TJUE núm. 2/13, apartado 191; y las sentencias de 21 de diciembre de 2011, N. S. y otros, C-411 y 493/10, EU:C:2011:865, apartados 78-80; y de 21 de febrero de 2013, Melloni, C-399/11, EU:C:2013:107, apartados 37 y 63.

112 Automatismo que ha sido criticado por algunos autores, véase, entre otros: Johan CALLEWAERT, «To Accede or Not to Accede: European Protection of Fundamental Rights at the Crossroads", Journal européen des droits de l'homme, núm. 4, 2014, pp. 496-513, p. 507; Valsamis MITSILEGAS, «The Limits of Mutual Trust in Europe's Area of Freedom, Security and Justice: From Automatic Inter-State Cooperation to the Slow Emergence of the Individual», Yearbook of European Law, 2012, pp. 319 y ss.; Wolfgang WEIB, «The EU Human Rights Regime Post Lisbon: Turning the CJEU into a Human Rights Court?», en Sonia MORANO-FOADIEL y Lucy VICKERS, Fundamental Rights in the EU - A Matter for Two Courts, Oregon-Oxford-Portland, 2015, pp. 69 y ss., pp. 83 y ss. Sobre esta problemática, véase de forma más general Olivier DE SCHUTTER y Françoise TULKENS, "Confiance mutuelle et droits de l'homme - La Convention européenne des droits de l'homme et la transformation de l'intégration européenne», en Paul MARTENS (coord.), Liège, Strasbourg, Bruxelles, parcours des droits de l'homme: Liber amicorum Michel Melchior, Anthemis, Limal, 2010, pp. 939 y ss.; Suliane NEVEU, «Reconnaissance mutuelle et droits fondamentaux: quelles limites a la coopération judiciaire pénale?», RTDH, 2016, pp. 119 y ss.

113 En una resolución parlamentaria dirigida a la Comisión Europea para que revise la orden europea de detención y entrega, el Parlamento Europeo manifestaba sus dudas a este respecto, Véase Resolución núm. 2013/2019(INL), de 27 de febrero de 2014. 
En efecto, ante esta disyuntiva de seguir la jurisprudencia del TJUE basada en la confianza mutua o la del TEDH más inclinada hacia un escrupuloso respeto de los derechos fundamentales se están viendo confrontadas en los últimos tiempos las jurisdicciones supremas de algunos Estados miembros y las respuestas están siendo discutibles si las apreciamos exclusivamente desde la perspectiva de la primacía, unidad y efectividad del derecho de la Unión; o integradoras si ponemos el acento en un enfoque intersistémico.

Puede verse en este sentido el fallo dictado por la Corte Suprema del Reino Unido en el asunto Eritrea ${ }^{114}$, en el que se planteaba el retorno a Italia de un solicitante de asilo, alegando que en este último país existían deficiencias sistémicas tanto en el procedimiento, como en las condiciones de recepción. Tras realizar una revisión crítica de la jurisprudencia del TJUE ${ }^{115}$, la Corte Suprema retuvo y aplicó una doctrina similar a la establecida posteriormente por el TEDH en el asunto Tarakhel vs. Suiza ${ }^{116}$. Y con respecto a la orden europea de detención, esta misma jurisdicción ha rechazado la entrega si constituye una interferencia desproporcionada en el derecho a la vida familiar de una madre y sus hijos en el marco del art. $8 \mathrm{CEDH}$. Dependiendo de las circunstancias, el interés superior

${ }^{114}$ Corte Suprema del Reino Unido, $R$ (on the application of Estado miembro (Eritrea)) (Appellant) vs. Secretary of State for the Home Department (Respondent), [2014] UKSC, 19 de febrero de 2014.

115 Ibid., apartado 48: "Before examining what CJEU said on this issue, it can be observed that an exclusionary rule based only on systemic failures would be arbitrary both in conception and in practice. There is nothing intrinsically significant about a systemic failure which marks it out as one where the violation of fundamental rights is more grievous or more deserving of protection. And, as a matter of practical experience, gross violations of article 3 rights can occur without there being any systemic failure whatsoever.»

116 Ibid:: "The removal of a person from a member state of the Council of Europe to another country is forbidden if it is shown that there is a real risk that the person transferred will suffer a treatment contrary to article 3 of ECHR». Poco después, esta misma jurisdicción británica afirmó en un fallo de 25 de marzo de 2015 en el que se debatía si era contrario al derecho de la Unión la privación de la nacionalidad británica a un ciudadano y el consiguiente riesgo de que deviniera un apátrida: «[...] unless the Court of Justice has had conferred upon it under domestic law unlimited as well as un appealable power to determine and expand the scope of European law, irrespective of what the Member States clearly agreed, a domestic court must ultimately decide for itself what is consistent with its own domestic constitutional arrangements", Corte Suprema del Reino Unido, Pham v Secretary of State for the Home Department, de 25 de marzo de 2015, [2015] UKSC 19. 
de los menores puede prevalecer, según afirma la jurisdicción británica, sobre el interés público en realizar la entrega, en particular, si los delitos cometidos en el Estado miembro de emisión no revisten especial gravedad en comparación con el daño que se infligiría a los menores ${ }^{117}$.

Y no se trata de una reacción aislada, sino que otros tribunales también han establecido objeciones más o menos similares ${ }^{118}$ e incluso el Tribunal

117 F.-K. vs. Polish Judicial Authority, [2012] UKSC 25, https://www.supremecourt.uk/ cases/uksc-2012-0039.html (consultado por última vez el 26 de octubre de 2016). Aunque sin relación con el ELSJ, sino con la política de medio ambiente, también debemos mencionar el asunto HS2 Action Alliance Ltd, $R v$ The Secretary of State for Transport \& Anor [2014] UKSC 3 (22 de enero de 2014), en el que por primera en su historia, la Corte Suprema citó la doctrina del TC alemán sobre los límites a la integración europea, tras lo cual afirmó: «A decision of the Court of Justice should not be read by a national court in a way that places in question the identity of the national constitutional order», añadiendo que la jurisprudencia del TJUE debía entenderse en el contexto de la relación de cooperación con las jurisdicciones supremas de los Estados miembros.

118 Así, la Sala de lo Penal de la Corte de Casación francesa en una Sentencia de 12 de abril de 2016, Crim. 12 avril 2016, FR:CCASS:2016:CR02480, en https://www. legifrance.gouv.fr/affichJuriJudi.do?idTexte=JURITEXT000032412585, en la que se debatía la oposición de un ciudadano francés a ser trasladado a los Países Bajos para ejecutar una pena de seis meses por tráfico de estupefacientes. Se basaba en que la Sentencia había sido dictada en rebeldía, solicitando a título subsidiario cumplir la pena en Francia dada su nacionalidad y sus lazos familiares y profesionales con este país. La Corte de Casación consideró que el tribunal de instancia debería haber examinado el respeto del art. 8 CEDH sobre la vida familiar. De la misma forma, el Tribunal Supremo de Suecia ha requerido a sus tribunales inferiores para que sigan la doctrina del TJUE excepto que un determinado acto constituya una clara violación del CEDH, Sentencia de 25 de febrero de 2014, 461-11 BillerudKorsnäs Sweden Ltd. vs. Agencia sueca de protección del medioambiente (Naturskyddsverket), NJA 2014,79, en inglés puede encontrarse en http://fra.europa.eu/en/caselaw-reference/sweden-supreme-court-461-11 (webs consultadas por última vez el 26 de octubre de 2016). Puede verse, asimismo, el el fallo del TC de Chipre de 7 de noviembre de 2005 en el asunto 294/2005; el fallo del Höjesteret de Dinamarca en el asunto U $1998.800 \mathrm{H}$; el fallo del TC italiano en el asunto Frontini, núm. 183/1973, 1974 Giur. Cost. 330; el fallo del TC polaco de 17 de abril de 2005, núm. P I/05. Sobre esta problemática puede verse, entre otros, Dawid MIASIK, «Application of General Principles of EC Law by Polish Courts - Is the European Court of Justice Receiving a Positive Feedback?», en Ulf BERNITZ, Joakim NERGELIUS y Cecilia CARDNER (eds.), General Principles of EC Law in a Process of Development, Kluwer Law International, Alphen aan den Rhijn, 2008, p. 357-92. 
Constitucional alemán, en una Sentencia de 15 de diciembre de 2015, desarrolla por primera vez un control de identidad del derecho europeo sobre la ejecución de una orden de detención. Se juzgaba en dicho asunto si debía entregarse a Italia un ciudadano americano que había sido condenado en rebeldía en 1992 por la Corte di Appello de Florencia a treinta años de prisión por pertenencia a banda armada y tráfico de estupefacientes. Ante el absoluto desconocimiento de su condena y la imposibilidad de obtener un nuevo proceso en Italia, la máxima jurisdicción germana subraya que en presencia de elementos fácticos que den a pensar que en caso de traslado hacia el Estado miembro emisor no serán respetadas las exigencias derivadas de la dignidad de la persona, tanto la Ley Fundamental como el derecho de la Unión impondrían al juez alemán informarse sobre la situación procesal y personal a la que se enfrentará dicho individuo en el Estado miembro emisor y, si no existen garantías, renunciar a su traslado, debiéndose realizar un examen individualizado en cada asunto ${ }^{119}$. De esta forma, las autoridades judiciales nacionales estarían, no solo autorizadas, sino obligadas a examinar si los requisitos de conformidad con el Estado de derecho se han cumplido, rechazando la entrega en caso negativo incluso si el TJUE se pronuncia de otro modo ${ }^{120}$. La jurisdicción constitucional alemana apoya su decisión sobre el art. 4 (2) TUE que protege la identidad nacional de los Estados miembros inherente a sus estructuras fundamentales políticas y constitucionales.

119 Auto del Tribunal Constitucional alemán de 15 de diciembre de 2015, R., 2 BvR 2735/14. Sobre este importante fallo, véase, entre otros, Xabier ARZOZ SANTISTEBAN, «Karlsruhe rechaza la Doctrina Melloni del Tribunal de Justicia y advierte con el control de la identidad constitucional», REDE, núm. 58, 2016, pp. 109-141; en este volumen de la Revista de Derecho Comunitario Europeo, Miguel AZPITARTE SÁNCHEZ, «Integración europea y legitimidad de la jurisdicción constitucional»; Editorial, «Sandwiched Between Strasbourg and Karlsruhe: EU Fundamental Rights Protection", European Constitutional Law Review, vol. 12, 2016, pp. 213-222; Marguerite GUIRESSE, «Quand le juge constitutionnel allemand encadre la confiance mutuelle: réflexions sur le juge européen des droits fondamentaux», en http://www. gdr-elsj.eu/2016/02/08 (consultado por última vez el 26 de octubre de 2016); Catherine HAGUENAU-MOIZARD, "Identité constitutionnelle et mandat d'arrêt européen: la exploitation de la jurisprudence Melloni par la Cour constitionnelle allemande», Europe, núm. 3, 2016, pp. 37 y ss.; Julian NOWAG, «EU Law, Constitutional Identity, and Human Dignity: A Toxic Mix? Bundesverfassungsgericht: $M r R »$, CMLRev., vol. 53, 2016, pp. 1441-1454.

120 BVerfG, 2 BvR 2735/14, de 15 de diciembre de 2015, apartado 82. 
Aunque puede ser criticable que la jurisdicción de Karlsruhe no planteara una cuestión prejudicial, creemos que sería altamente improbable que el TJUE se pronunciara en un sentido distinto. En primer lugar, porque la Directiva (UE) núm. 2016/343 establece que cuando los sospechosos o acusados no estén presentes en el juicio deberán tener derecho a un nuevo juicio $\mathrm{u}$ otras vías de recurso ${ }^{121}$. Y, en segundo lugar, porque a pesar del diferente contexto fáctico, este fallo del TC alemán es bastante semejante al dictum del TJUE en el asunto Aranyosi y Caldararu, protegiéndose en ambos la dignidad humana. Por el contrario, a pesar de sus semejanzas fácticas, no es necesariamente incompatible con el fallo del TJUE en el asunto Melloni. En efecto, a diferencia de este último, el perseguido en Alemania no había tenido ningún conocimiento de que había sido procesado y condenado en Italia y, como consecuencia de ello, el fundamento de la Decisión Marco sobre la orden europea de detención era diferente al cuestionado en el asunto Melloni. Además, en la tramitación de la cuestión prejudicial en este último asunto nuestro país no alegó que la obtención de un nuevo juicio en Italia formara parte de nuestra identidad constitucional —art. 4 (2) TUE— ${ }^{122}$ y de ahí que el TJUE no abordara esta cuestión.

Sea como fuere, de lo que no cabe duda es que esta decisión del Tribunal Constitucional alemán abre la vía a futuros controles similares en el seno de otros ordenamientos jurídicos nacionales. En realidad, ni es algo nuevo que existan disposiciones constitucionales en ciertos Estados miembros que protegen su identidad constitucional ante el proceso de integración europea $^{123}$, limitándose la virtualidad del fallo del TC alemán a recordarnos esta

${ }^{121}$ Arts. 8 y 9 de la Directiva (UE) 2016/343 del Parlamento Europeo y del Consejo de 9 de marzo de 2016 por la que se refuerzan en el proceso penal determinados aspectos de la presunción de inocencia y el derecho a estar presente en el juicio, DO L 65/1, de 11 de marzo de 2016; a incorporar antes del 1 de abril de 2018.

${ }^{122}$ Lo que llevó al abogado general Bot a afirmar en sus conclusiones en este asunto: «[...] los debates que han tenido lugar tanto en el Tribunal Constitucional como ante el Tribunal de Justicia me convencen de que la determinación del alcance del derecho a un proceso equitativo y del derecho de defensa en caso de sentencias dictadas en rebeldía no puede afectar a la identidad nacional del Reino de España», EU:C:2012:600, apartado 60 .

${ }^{123}$ En efecto, en los últimos años otros fallos similares han sido dictados en otros Estados miembros. Puede verse en este sentido, Consejo Constitucional de Francia, Decisión de 27 de julio de 2006 sobre la ley relativa al derecho de autor, en la que el Tribunal expone los principios inherentes a su identidad constitucional en el contexto de la incorporación de directivas. O en Italia, donde la Corte Constitucional italiana desarrolló mediante dos decisiones de 24 de octubre de 2007 la idea de control constitu- 
cuestión; ni es algo nuevo que se cuestione desde algunas jurisdicciones supremas nacionales la primacía, unidad y efectividad del derecho de la Unión. En realidad, esto ya ocurrió en los años sesenta, principalmente frente a las jurisdicciones francesas, y solo fue con persuasión, diálogo y comprensión mutua como aquella batalla acabó siendo ganada para el derecho europeo. Una batalla de similares características parece cuestionar hoy la autonomía del derecho de la Unión, su primacía y el principio de confianza mutua. Y solo podría encontrar su cauce de solución a través de la asimilación de que el derecho europeo no es tan autónomo de los ordenamientos constitucionales y del derecho internacional de los derechos humanos como el TJUE parece imponer. En relación con el principio de reconocimiento mutuo las limitaciones vienen, de una parte, del TEDH, que trata de asegurar que el nivel de protección en la Unión no caiga por debajo del estándar mínimo ${ }^{124}$; y de otra, de algunos tribunales constitucionales nacionales, que tratan de empujar al TJUE hacia un respeto escrupuloso del núcleo esencial de los derechos fundamentales, postergando si es preciso los principios de unidad y efectividad del derecho de la Unión ${ }^{125}$.

\section{CONCLUSIONES}

El fallo de la Gran Sala del TEDH en el asunto Avotinšs vs. Letonia reviste especial importancia por dos razones fundamentales. Desde el Dictamen del TJUE núm. 2/13 es la primera vez que el TEDH confirma la plena vigencia de la presunción de equivalencia, cerrando el paso a las murmuraciones que habían surgido. Segundo, y quizás lo más importante, es la primera vez que el TEDH aborda de manera sustancial la convencionalidad del principio de confianza mutua a través de un profundo análisis del funcionamiento del sistema de reconocimiento mutuo de sentencias extranjeras. Si hacemos abstracción, lo fundamental es que el TEDH avaló la idea de que los órganos jurisdiccionales nacionales pueden presumir la compatibilidad con los derechos fundamentales de las sentencias dictadas por los tribunales de otro. Es cierto,

cional en la aplicación e interpretación de normas europeas de manera coherente con las normas constitucionales. Se trataba, en particular, de las disposiciones del CEDH.

$124 \mathrm{TEDH}$, Avotinšs vs. Letonia [GS], $\$$ 116: «[...] la Cour [...] doit [...] s'assurer que les dispositifs de reconnaissance mutuelle ne laissent subsister aucune lacune ou situation particulière donnant lieu à une insuffisance manifeste de la protection des droits de l'homme garantis par la Convention."

125 Editorial, European Constitutional Law Review, vol. 12, núm. 2, 2016, pp. 213-222, p. 222. 
sin embargo, que aunque legitima este principio, advirtió de los riesgos de su aplicación mecánica porque pueden conducir a la constatación de una deficiencia manifiesta. Es la completa abdicación de la competencia de control por parte de los tribunales del Estado de ejecución sobre los tribunales del Estado requirente lo que no parece considerarse adecuado, desposeyendo a aquellos de su competencia para pronunciarse en los supuestos de violaciones graves en el Estado de origen. Por ello, lejos de la complacencia, este fallo del TEDH debe hacer reflexionar a las instituciones de la Unión sobre la necesidad de emprender una reforma porque todo parece indicar que la plena convencionalidad de los instrumentos del ELSJ basados en el reconocimiento mutuo va a depender de que los tribunales internos retengan alguna posibilidad de controlar violaciones serias y manifiestas de los Derechos fundamentales. En efecto, el principio de confianza mutua se enfrenta al desafío de las garantías de los derechos fundamentales, en particular, de los arts. 3 y $6 \$ 1 \mathrm{CEDH}$. Tanto el TEDH en el asunto M. S. S. vs. Bélgica y Grecia como el TJUE en los asuntos N. S., Aranyosi y Căldăraru o Petruhbin han desarrollado motivos implícitos de rechazo del reconocimiento mutuo cuando las mismas bases de la confianza mutua son altamente cuestionables. El sistema también se enfrenta al desafío por las dudas acerca del Estado de derecho y la Administración de Justicia en ciertos Estados miembros. Por otra parte, el grado de automaticidad del reconocimiento mutuo en estos distintos instrumentos no es uniforme, permitiendo una diversa invocación de los derechos fundamentales. Todo ello parece llamar a las instituciones para que emprendan una reforma a fin de dotarlos de homogeneidad y, especialmente, insertar cláusulas implícitas de control ante supuestos de infracciones manifiestas. Se trata, por tanto, de encontrar el equilibrio entre un reconocimiento mutuo de gran alcance, dinámico y dotado de un alto grado de resolución con cláusulas residuales de control que garanticen la plena convencionalidad de estos instrumentos.

Desde una perspectiva más general, conviene que no nos llevemos a engaño. Había mimbres suficientes para decidir la ausencia de discrecionalidad, evitar la aplicación de la doctrina Bosphorus y condenar a Letonia. Sin que lleguemos a calificar el fallo de político, como hace algún autor ${ }^{126}$, preferimos poner el acento sobre el alto grado de persuasión que despliega el TEDH con esta forzada aplicación de la doctrina de la presunción equivalente a fin de tratar de despejar las múltiples dudas expresadas por el TJUE en el Dictamen núm. 2/13. Así, desde la perspectiva de una futura adhesión, o bien se acepta por las demás partes en el CEDH una cláusula como la propuesta del Comité MEIJERS, que creemos que representa un adecuado tertium genus entre las jurisprudencias de ambos tribunales; o caemos en la cuenta de que fallos como

126 Marta REQUEJO ISIDRO, «Avotinš̌ c. Letonia, ...», op. cit.,nota 2, p. 199 
Avotiňš vs. Letonia garantizan una suficiente coordinación de los arts. 53 de la CDFUE y del CEDH y una adecuada consideración de las peculiaridades del ELSJ. Al fin y al cabo, la Gran Sala del TEDH parece comprometerse a renunciar al escrutinio de los instrumentos del ELSJ basados en la confianza mutua en tanto en cuanto los jueces realicen un examen integrado de la protección de los derechos fundamentales cada vez que se aleguen conculcaciones serias. 